\title{
Primary Repair, Reconstruction, and Suture Tape Augmentation All Provide Excellent Outcomes for Lateral Ligament Instability: A Systematic Review
}

\author{
Matthew L. Vopat, M.D., Brennan Lee, Anthony C. Mok, B.S., \\ Maaz Hassan, Brandon Morris, M.D., Armin Tarakemeh, B.A., Rosey Zackula, B.A, \\ Scott Mullen, M.D., Paul Schroeppel, M.D., and Bryan G. Vopat, M.D.
}

\begin{abstract}
Purpose: To analyze the literature to compare outcomes and complications following primary lateral ankle ligament repair compared with lateral ankle ligament reconstruction and the suture tape augmentation in patients with lateral ankle instability. Methods: Following the Preferred Reporting Items for Systematic Review and Meta-Analyses (PRISMA) criteria, a systematic literature review using the PubMed/Ovid Medline database was performed (October 11, 1947, to October 1, 2019). Clinical trials that included all the following criteria were considered eligible; published in the English language; patients undergoing primary lateral ankle repair or reconstruction with/without autograft or allograft (anterior talofibular ligament, anterior talofibular ligament + calcaneofibular ligament) or suture tape augmentation; a follow-up at least 1 year; reported least 1 of the measured outcomes (The American Orthopaedic Foot Ankle Score, Karlsson Score, return to sport [RTS], complications, skin wound complications, reoperation). Surgical techniques were evaluated, and studies were subdivided by the following categories: primary repair (PR), reconstruction with graft (GR), and suture tape augmentation (STA). Complications, radiographic outcomes, functional outcome scores, and RTS were analyzed. Results: A total of 41 of 1,991 studies met the criteria for final analysis. This included 1,920 patients who underwent surgical intervention for chronic lateral instability with at least a l-year follow-up. There were 350 patients who had GR, 1,486 who underwent the PR, and 84 who had STA. GR group appeared to have the lowest rate of complications: GR $3.1 \%$ ( 11 of 350), PR 4.2\% (63 of 1486), and STA 10.7\% (9 of 84). Postoperative American Orthopaedic Foot Ankle Score ranged from 89.0 to 95.1 for GR and 90.0 to 98.8 for PR. Postoperative Karlsson scores ranged from 80.9 to 94.4 for GR and from 89.2 to 94.1 for PR. Anterior drawer postoperative scores ranged from 1.4 to $30.3 \mathrm{~mm}$ for GR, 2.7 to $8.6 \mathrm{~mm}$ for $\mathrm{PR}$, and 4.1 to $4.2 \mathrm{~mm}$ for STA. Postoperative talar tilt ranged from 2.4 to $7.3^{\circ}$ for $\mathrm{GR}, 1.9$ to $6.0^{\circ}$ for $\mathrm{PR}$, and 3.6 to $4.5^{\circ}$ for STA. RTS ranged from 9.5 to 20.4 weeks for the PR group; one study reported a RTS of 10.6 weeks for STA. Conclusions: Excellent outcomes were noted across all intervention groups. Current literature may suggest there is no difference in functional outcomes between patients treated with PR versus GR. However, there may be a potential improvement in functional outcomes with PR versus STA. Level of Evidence: Level IV, systematic review of Level I to Level IV studies.
\end{abstract}

\footnotetext{
A nkle injuries make up about $40 \%$ of all sports and recreational activity injuries, especially in sports such as basketball, soccer, cross-country running, and more. ${ }^{1}$ Typically, these ankle injuries are associated with a ligament rupture, primarily the anterior

From the Department of Orthopaedics, University of Kansas School of Medicine - Wichita, Wichita, Kansas, U.S.A. (M.L.V.); University of Kansas School of Medicine - Wichita, Wichita, Kansas, U.S.A. (B.L., M.H.); University of Kansas Medical Center - Wichita Campus, Wichita, Kansas, U.S.A. (R.Z.). University of Kansas School of Medicine, Kansas City, Kansas, U.S.A. (A.C.M.); and Medical Center, Department of Sports Medicine and Orthopaedics, Kansas City, Kansas, U.S.A. (B.M., A.T., S.M., P.S., B.G.V.).

The authors report that they have no conflicts of interest in the authorship and publication of this article. Full ICMJE author disclosure forms are available for this article online, as supplementary material.

Received May 1, 2020; accepted September 30, 2021.
}

talofibular ligament (ATFL) and calcaneofibular ligament. ${ }^{2}$ Most of these ankle injuries can be treated effectively with conservative methods; however, some patients will not respond to conservative treatment and continue to have chronic symptoms or chronic lateral

Address correspondence to Matthew L. Vopat, M.D., Department of Orthopaedics, University of Kansas School of Medicine-Wichita, Via Christi Health, 929 N. St. Francis, Room 4076,Wichita, KS 67214.E-mail:mvopat@ kumc.edu

(C) 2021 Published by Elsevier Inc. on behalf of the Arthroscopy Association of North America. This is an open access article under the CC BY-NC-ND license (http://creativecommons.org/licenses/by-nc-nd/4.0/).

2666-061X/20649

https://doi.org/10.1016/j.asmr.2021.09.023 
ankle instability (CLAI). ${ }^{3}$ These chronic symptoms can be severely disabling, especially in patients with high use of ankle joint function, such as athletes. ${ }^{4}$ After nonresponse to conservative treatment, surgical repair of these injuries is indicated. ${ }^{3}$ The use of the Broström technique has increased for the surgical repair of these injuries, showing excellent outcomes and becoming the gold standard in treating CLAI when operative intervention is required. ${ }^{5}$

However, there are multiple techniques used for the surgical treatment of CLAI. These techniques include anatomic direct repair with or without local tissue augmentation, anatomic ligament reconstruction using either an autograft or an allograft, and arthroscopic repair. $^{6}$ Anatomic direct repair uses native ligament remnants with or without local tissue for added support whereas anatomic ligament reconstruction is used when the patient has poor ligament remnants. ${ }^{6}$ Autograft ligament reconstruction has superior tissue quality but runs the risk of donor-site morbidity and increased postoperative pain whereas allograft ligament reconstruction avoids these risks but does not have the quality of tissue from an autograft. ${ }^{6}$ Arthroscopic repair is performed using mainly suture anchors with the idea that this procedure reduces postoperative pain and complications while also speeding up recovery. ${ }^{6}$ Ligament repair augmentation using suture-tape is a new novel technique for CLAI. ${ }^{7}$ This procedure theoretically reduces the likelihood of needing an anatomic ligament reconstruction. ${ }^{7}$ Recent biomechanical studies have shown good success of an augmented ATFL reconstruction using suture tape, but more clinical evidence is needed. ${ }^{7}$

There is little agreement on what surgical procedure should be used on patients with CLAI demonstrated by the many different techniques that have been described. More research is needed about the benefits of each technique to better assess which technique is right for each individual patient. The purpose of this review is to analyze the literature to compare outcomes and complications following primary lateral ankle ligament repair compared with lateral ankle ligament reconstruction and the suture tape augmentation in patients with lateral ankle instability. The hypothesis of this study is that results from primary lateral ankle ligament repair versus lateral ankle ligament reconstruction and suture tape augmentation would have differing outcomes.

\section{Methods}

\section{Search Strategy and Study Selection}

This study followed the Preferred Reporting Items for Systematic Review and Meta-Analyses (PRISMA) guidelines. Since this study was a systematic review of published studies, institutional review board approval was not required. A systematic literature review performed on November 1, 2019, was conducted using the PubMed/Ovid/MEDLINE database; dates of publication was limited to October 11, 1947, through October 1, 2019. The main key words "lateral ankle repair; Lateral ankle ligament repair; Lateral ankle ligament reconstruction; Broström; Broström-Gould; Broström Gould; Modified Broström" were used in the electronic search. Two investigators performed a separate, manual study selection from this list to exclude repetitions and to select those specifically related to discussed item. In case of any discrepancies in article selection between the 2 investigators, a third investigator was involved. Only studies published in the English language were included in this study. The reference list of each selected article also was screened for additional articles that met the inclusion criteria. Due to a lack of high-level evidence looking at the comparison between these surgical techniques, nonrandomized trials were included. We felt it was more valuable to include all literature on these surgical techniques and their outcomes.

\section{Eligibility Criteria}

Clinical trials that included all the following criteria were considered eligible; published in the English language; patients undergoing primary lateral ankle repair or reconstruction with/without autograft or allograft (ATFL, ATFL + calcaneofibular ligament) or suture tape augmentation; a follow-up at least 1 year; reported least one of the measured outcomes (The American Orthopaedic Foot Ankle Score [AOFAS], Karlsson Score, return to sport [RTS], complications, skin wound complications, reoperation). Studies were excluded if they included patients with any of the following: those who underwent revision ligament repair, reconstruction, or suture tape augmentation; who had concomitant talar chondral or osteochondral repair or reconstructive procedures; who had concomitant peroneal tendon procedures (peroneal tendon debridement, tendon repair); who underwent concomitant superior peroneal retinaculum repair; had concomitant treatment of hindfoot or forefoot pathology (calcaneal osteotomy for cavovarus reconstruction, subtalar arthrodesis); and/or who had a syndesmosis repair or ankle fracture open reduction and internal fixation.

\section{Data Extraction and Quality Appraisal}

Operative techniques for each study were reviewed and divided into 3 categories; primary repair group (PR), graft reconstruction group (GR), and suture tape augmentation group (STA). Patients treated with the modified Broström technique were included in the PR group. ${ }^{8}$ The GR group was further subdivided into autograft or allograft. STA was defined as using additional suture tape fixation that was anchored to both 
Fig 1. The wide variety and inconsistency with which functional outcomes were measured across all the used studies is shown.

\section{Use of Functional Analysis Scores Among Included Studies}

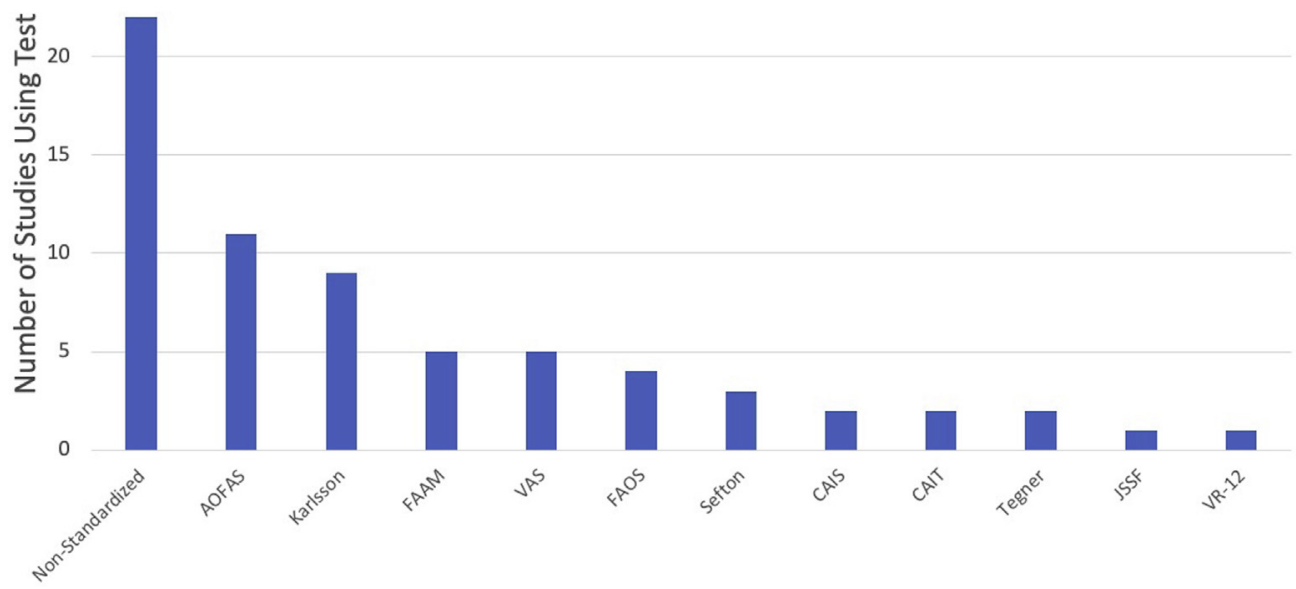

Functional Analysis Used

the fibula and talus. RTS, talar tilt, anterior drawer, functional outcome scores (AOFAS, Karlsson score), and total complications of 3 populations were recorded and compared. Skin wounds were then subdivided out of the total complications and were defined as either having one of the following: wound dehiscence, wound
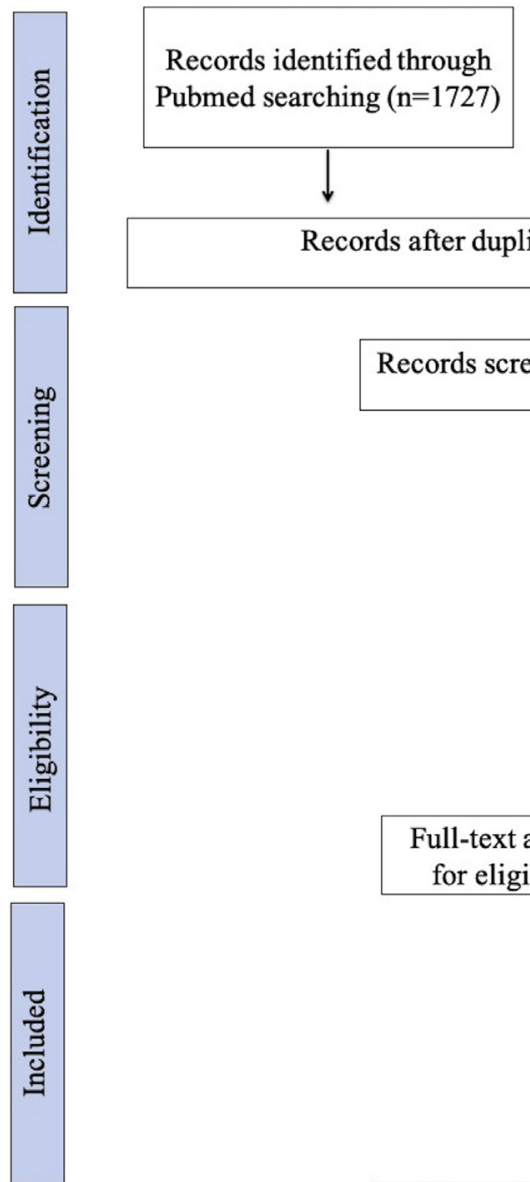

\section{Records identified through}

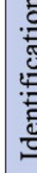

Records after duplicates removed ( $\mathrm{n}=1718)$

Records screened $(\mathrm{n}=1718)$

Records of non-lateral ligam repair/reconstruction/s augmentation $(\mathrm{n}=829)$

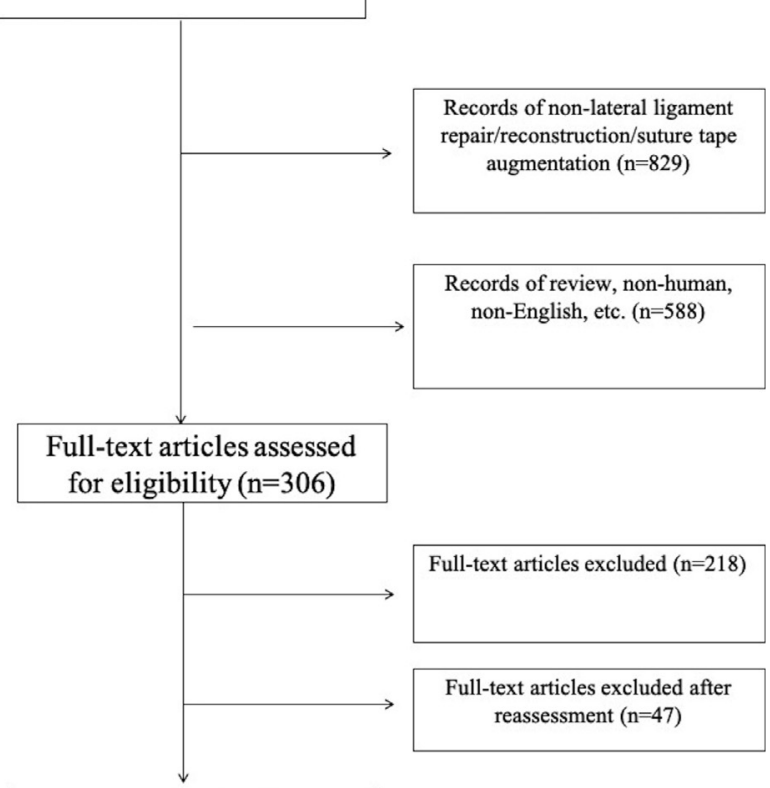

Studies included in quantitative analysis $(n=41)$
Fig 2. Preferred Reporting Items for Systematic Review and Meta-Analyses (PRISMA) flowchart for article selection. 
Table 1. Studies by Operative Technique

\begin{tabular}{|c|c|c|c|c|c|c|c|c|c|}
\hline Author & Year & $\begin{array}{c}\text { Graft } \\
\text { Reconstruction }\end{array}$ & $\begin{array}{l}\text { Primary } \\
\text { Repair }\end{array}$ & $\begin{array}{c}\text { Suture } \\
\text { Tape } \\
\text { Augmentation }\end{array}$ & Male & Female & Average Age, y (Range) & $\begin{array}{c}\text { Range of } \\
\text { Follow-Up (Months) }\end{array}$ & $\begin{array}{l}\text { Level } \\
\text { of } \\
\text { Evidence }\end{array}$ \\
\hline \multicolumn{10}{|l|}{ Graft reconstruction } \\
\hline Giannini et al. ${ }^{15}$ & 2014 & 21 & & & $\mathrm{n} / \mathrm{a}$ & $\mathrm{n} / \mathrm{a}$ & $25.9(\mathrm{n} / \mathrm{a})$ & $24-96$ & IV \\
\hline Miyamoto et al. ${ }^{16}$ & 2014 & 33 & & & 23 & 10 & $27.1(18-43)$ & 24 & III \\
\hline Nakata et al. ${ }^{17}$ & 2000 & 20 & & & $\mathrm{n} / \mathrm{a}$ & $\mathrm{n} / \mathrm{a}$ & $20.2(15-31)$ & $37.2-120$ & IV \\
\hline Park et al. ${ }^{18}$ & 2016 & 30 & & & 23 & 7 & $23.9(17-54)$ & $12-33$ & IV \\
\hline Sammarco et al. ${ }^{4}$ & 1999 & 30 & & & 17 & 13 & $30.0(12-47)$ & $24-64$ & IV \\
\hline Ventura et al. ${ }^{22}$ & 2018 & 20 & & & 12 & 8 & $29.2(18-40)$ & 180 & III \\
\hline Wang et al. ${ }^{19}$ & 2013 & 25 & & & 14 & 11 & $32.4(17-62)$ & $12-56$ & IV \\
\hline Wang et al. ${ }^{20}$ & 2017 & 19 & & & 10 & 9 & $27.9(19-41)$ & $12-40$ & IV \\
\hline Xu et al. ${ }^{6}$ & 2014 & 68 & & & 41 & 27 & $32.8(\mathrm{n} / \mathrm{a})$ & $21.8-40.2$ & III \\
\hline Youn et al. ${ }^{21}$ & 2012 & 14 & & & 9 & 5 & $29.1(20-53)$ & $12-40$ & IV \\
\hline $\begin{array}{l}\text { Total graft } \\
\text { reconstruction }\end{array}$ & $\mathrm{n}=10$ & 280 & & & 149 & 90 & & & \\
\hline \multicolumn{10}{|l|}{ Primary repair } \\
\hline Agoropoulos et al. ${ }^{24}$ & 1997 & & 75 & & 60 & 15 & $\mathrm{n} / \mathrm{a}(15-53)$ & $12-180$ & IV \\
\hline Alghern et al. ${ }^{25}$ & 1989 & & 76 & & 50 & 26 & $28.0(16-55)$ & $12-70$ & IV \\
\hline Brodsky et al. ${ }^{5}$ & 2005 & & 73 & & 29 & 44 & $31.0(15-61)$ & $14-120$ & IV \\
\hline Buerer et al. ${ }^{8}$ & 2013 & & 41 & & 16 & 25 & $33.7(18-60)$ & $13-72$ & IV \\
\hline Burn et al. ${ }^{10}$ & 2013 & & 41 & & 16 & 25 & $33.7(18-60)$ & $24-34$ & IV \\
\hline $\begin{array}{l}\text { Cho et al. }{ }^{26,27} \\
\text { Transosseous } \\
\text { suture }\end{array}$ & 2012 & & 20 & & 12 & 8 & $33.9(21-42)$ & $24-33$ & I \\
\hline \multirow{2}{*}{$\begin{array}{l}\text { Cho et al. } \\
\quad \text { Suture anchor }\end{array}$} & 2012 & & 20 & & 11 & 9 & $30.7(15-44)$ & $24-34$ & I \\
\hline & 2015 & & 24 & & 17 & 7 & $23.1(17-28)$ & $24-41$ & II \\
\hline Evans et al. ${ }^{28}$ & 1984 & & 50 & & 39 & 11 & $24.7(16-35)$ & 24 & III \\
\hline Giannini et al. ${ }^{13}$ & 2014 & & 17 & & $\mathrm{n} / \mathrm{a}$ & $\mathrm{n} / \mathrm{a}$ & $25.9(\mathrm{n} / \mathrm{a})$ & $24-96$ & IV \\
\hline Gould et al. ${ }^{29}$ & 1980 & & 50 & & 34 & 16 & $\mathrm{n} / \mathrm{a}$ & $12-\mathrm{n} / \mathrm{a}$ & IV \\
\hline Hamilton et al. ${ }^{30}$ & 1993 & & 27 & & 14 & 13 & $28.1(18-59)$ & $30-132$ & IV \\
\hline Iwao et al. ${ }^{31}$ & 2014 & & 10 & & 5 & 5 & $27.0(16-30)$ & $12-\mathrm{n} / \mathrm{a}$ & III \\
\hline Jarvela et ${ }^{32}$ & 2002 & & 32 & & 20 & 12 & $27.0(13-43)$ & $2.1-4.0$ & III \\
\hline Jaskulka et al. ${ }^{33}$ & 1988 & & 268 & & 135 & 133 & $25.9(12-62)$ & $24-72$ & IV \\
\hline Jeong et al. ${ }^{34}$ & 2016 & & 45 & & 19 & 26 & $32.0(17-75)$ & $24-70.3$ & III \\
\hline \multirow[t]{4}{*}{ Karlsson et al. ${ }^{35-38}$} & 1988 & & 148 & & 93 & 55 & $23.0(17-42)$ & & IV \\
\hline & 1989 & & 60 & & 35 & 25 & $23.0(18-39)$ & $24-60$ & IV \\
\hline & 1995 & & 40 & & 22 & 18 & $24.0(17-35)$ & $24-n / a$ & IV \\
\hline & 1999 & & 30 & & 18 & 12 & $27.0(18-36)$ & $24-n / a$ & IV \\
\hline Keller et al. ${ }^{39}$ & 1996 & & 39 & & $\mathrm{n} / \mathrm{a}$ & $\mathrm{n} / \mathrm{a}$ & $33.8(\mathrm{n} / \mathrm{a})$ & $12-n / a$ & IV \\
\hline Lofvenberg et al. ${ }^{40}$ & 1994 & & 27 & & 21 & 6 & $30.0(16-54)$ & $12-83$ & II \\
\hline Matsui et al. ${ }^{41}$ & 2016 & & 37 & & 20 & 17 & $28.0(8-59)$ & 12 & III \\
\hline Messer et al. ${ }^{42}$ & 2000 & & 22 & & 10 & 12 & $27.2(15-44)$ & $18-72$ & IV \\
\hline Petrera et al. $^{43}$ & 2014 & & 49 & & 23 & 26 & $25.0(18-37)$ & $24-60$ & IV \\
\hline Porter et al. ${ }^{44}$ & 2019 & & 25 & & 13 & 12 & $24(16-41)$ & 60 & I \\
\hline Russo et al. ${ }^{45}$ & 2016 & & 18 & & 11 & 7 & $21.5(17-32)$ & $120-180$ & IV \\
\hline Saragaglia et al. ${ }^{46}$ & 1997 & & 32 & & 14 & 18 & $25.0(16-44)$ & $12-\mathrm{n} / \mathrm{a}$ & IV \\
\hline Schmidt et al. ${ }^{2}$ & 2004 & & 32 & & 32 & 0 & $\mathrm{n} / \mathrm{a}$ & $18-61$ & II \\
\hline Trichine et al. ${ }^{47}$ & 2017 & & 38 & & 38 & 0 & $24.2(19-31)$ & $30-86.4$ & III \\
\hline Ventura et al. $^{20}$ & 2018 & & 20 & & 11 & 9 & $27.4(18-40)$ & 180 & III \\
\hline Xu et al. ${ }^{6}$ & 2019 & & 28 & & $\mathrm{n} / \mathrm{a}$ & $\mathrm{n} / \mathrm{a}$ & $28.1(17-55)$ & $12-24$ & III \\
\hline Total primary repair & $\mathrm{n}=31$ & & 1514 & & 838 & 592 & & & \\
\hline \multicolumn{10}{|l|}{$\begin{array}{l}\text { Suture tape } \\
\text { augmentation }\end{array}$} \\
\hline Cho et al. ${ }^{49}$ & 2015 & & & 34 & 0 & 34 & $26.2(16-38)$ & $24-39$ & IV \\
\hline Cho et al. ${ }^{48}$ & 2015 & & & 28 & 19 & 9 & $29.5(18-43)$ & $24-52$ & IV \\
\hline Porter et al. ${ }^{44}$ & 2019 & & & 22 & 12 & 10 & $26.1(16-43)$ & 60 & I \\
\hline Xu et al. ${ }^{6}$ & 2019 & & & 25 & $\mathrm{n} / \mathrm{a}$ & $\mathrm{n} / \mathrm{a}$ & $26.6(16-50)$ & $12-24$ & III \\
\hline $\begin{array}{c}\text { Total suture tape } \\
\text { augmentation }\end{array}$ & $\mathrm{n}=4$ & & & 109 & 31 & 53 & & & \\
\hline
\end{tabular}

$\mathrm{n} / \mathrm{a}$, not available.

*Sex was not reported for 150 (7.9\%) cases. 
Table 2. Participant Demographics by Operative Technique

\begin{tabular}{|c|c|c|c|c|c|c|c|}
\hline \multirow[b]{2}{*}{ Operative Technique } & \multicolumn{2}{|c|}{ Sample Size } & \multicolumn{2}{|c|}{ Male } & \multicolumn{2}{|c|}{ Female } & \multirow{2}{*}{$\frac{\text { Average }}{\text { Age }}$} \\
\hline & $\mathrm{n}=1,920$ & $100.0 \%$ & $\mathrm{n}=1,078$ & $56.1 \%$ & $\mathrm{n}=755$ & $39.3 \%$ & \\
\hline Graft reconstruction & 350 & 18.2 & 199 & 10.4 & 110 & 5.7 & 28.4 \\
\hline General population & 296 & & 176 & & 100 & & De \\
\hline Primary repair & 1486 & 77.4 & 838 & 43.6 & 592 & 30.8 & 26.9 \\
\hline Athletes & 18 & & 11 & & 7 & & 21.5 \\
\hline General population & 1286 & & 688 & & 542 & & 27.0 \\
\hline General population & 62 & & 19 & & 43 & & 27.7 \\
\hline Unknown & 22 & & 42 & & 61 & & 32.3 \\
\hline
\end{tabular}

*Sex was not reported for $97(5.0 \%)$ cases.

drainage, and/or cellulitis. Reoperation rate also was evaluated for and analyzed between the 3 groups. The Karlsson score followed by the traditional scoring scale (0-100) that was first described Karlsson and Peterson. ${ }^{9}$ The following parameters were evaluated for the Karlsson Score: pain, swelling instability, stiffness, stair climbing, running, working activities, and support. ${ }^{9}$ The Karlsson score was interpreted as poor if $<60$, fair if 60 $\leq$ Karlsson $\leq 74$, good if $75 \leq$ Karlsson $\leq 84$, and excellent if $85 \leq$ Karlsson $\leq 100 .^{9}$ Similarly, AOFAS scoring scale $(0-100)$ was also used. ${ }^{10}$ The following parameters were also evaluated for AOFAS: pain, function, and alignment. ${ }^{11}$ The AOFAS score was interpreted as poor if $<50$, fair if $50 \leq$ AOFAS $\leq 74$, good if $75 \leq$ AOFAS $\leq 89$, and excellent if $90 \leq$ AOFAS $\leq 100 .{ }^{11}$ A variety of functional outcome measurement tools were used in all the studies, as seen in Fig 1. However, the Karlsson and AOFAS scores were most commonly used. The GR group was further subdivided to autograft or allograft and the above variables also were analyzed between these 2 populations. Assessment of methodologic quality was conducted with the Cochrane Collaboration Tool ${ }^{12}$ was performed by 2 reviewers (A.T. and M.H.; a third tiebreaker [M.V.] was designated in case of any disagreement).

\section{Statistical Analysis}

Statistical analysis was for the overall cohort of studies was conducted in IBM SPSS Statistics, version 26 (IBM Corp., Armonk, NY), with the criterion for alpha set at 0.05 as the level of significance. Data from each article were summarized by operative technique. Descriptive statistics was performed for each study, and parameters were analyzed. For each variable evaluated, the number and percentage of studies that reported the variable was calculated. Frequencies and percentages were reported for categorical variables; means and standard deviations were reported for continuous variables.

Meta-analyses were conducted in RStudio, using $\mathrm{R}$ version 4.0.1, following Harrer, Cuijpers, Furukawa, and Ebert 2019. ${ }^{13}$ Mixed-effects models (random-effects within subgroups and fixed-effects between subgroups) were conducted. The meta-analytical method included the inverse variance method, Sidik-Jonkman estimator for tau, ${ }^{2}$ Hartung-Knapp adjustment, and Hedges' g (bias corrected standardized mean difference). These methods were chosen because the number of studies were small and heterogeneity may be problematic. To determine the extent to which heterogeneity was present, the rule of thumb outlined in Higgins et al. ${ }^{12}$ was used to indicate the percentage of variability in effect sizes not caused by sampling error, where $\mathrm{I}^{2}=25 \%$ is low, $\mathrm{I}^{2}=50 \%$ is moderate, and $\mathrm{I}^{2}=75 \%$ is substantial heterogeneity. For each model, pre- and postoperative measures were compared using the standardized mean difference (SMD). A total of 4 models were developed: 2 for the functional measure (AOFAS and Karlsson scores) and 2 for the radiographic measure (anterior drawer and talar tilt).

\section{Results}

The initial PubMed/Ovid MEDLINE database search identified 1,992 articles. Of those, 1,685 articles were excluded because they did not meet the inclusion criteria (Fig 2). Of the remaining 307 studies, 89 were selected for initial screening. In total, 48 articles were critically reassessed, and 41 articles remained after the secondary screen. Table 1 shows the studies included in the analysis by operative technique; 10 studies used $\mathrm{GR}^{4,6,13-21}$ with $\mathrm{n}=280$ participants; 31 studies in $\mathrm{PR}^{2,5,8,10,22-46} \mathrm{n}=1,514$; and 4 studies reported $\mathrm{STA}^{7,42,47}$ in their surgical fixation, $\mathrm{n}=109$; for a total of 1,903 participants.

\section{Patient Demographics}

The analysis included 1,018 males and 735 females; sex was not reported for 150 patients. The ages ranged from 20.2 to 33.9 years, with 157 unreported. Table 2 shows participant demographics by operative technique and by athletes versus general population. The majority of participants had a primary repair procedure, were male, and were categorized as general population. 


\begin{tabular}{|c|c|c|c|c|c|c|c|c|c|}
\hline & $\begin{array}{l}\text { Selection } \\
\text { method }\end{array}$ & $\begin{array}{l}\text { Exposure } \\
\text { ascertainment }\end{array}$ & $\begin{array}{c}\text { Outcome } \\
\text { Ascertainment }\end{array}$ & $\begin{array}{c}\text { Alternative } \\
\text { outcome } \\
\text { explanation? }\end{array}$ & $\begin{array}{l}\text { Challenge/rechallenge } \\
\text { phenomenon? }\end{array}$ & $\begin{array}{l}\text { Dose- } \\
\text { response } \\
\text { effect? }\end{array}$ & $\begin{array}{l}\text { Follow up } \\
\text { long enough? }\end{array}$ & $\begin{array}{c}\text { Enough results } \\
\text { to } \\
\text { replicate/mak } \\
\text { e inferences? }\end{array}$ & $\begin{array}{l}\text { Total } \\
\text { Score }\end{array}$ \\
\hline $\begin{array}{l}\text { Agoropoulos, Z } \\
\text { et alas }\end{array}$ & v & $\checkmark$ & $x$ & $x$ & $x$ & $x$ & $\checkmark$ & $\checkmark$ & 4 \\
\hline Algherns et al15 & $\checkmark$ & $\checkmark$ & $\checkmark$ & $x$ & $x$ & $x$ & $\checkmark$ & $\checkmark$ & 5 \\
\hline Brodsky et als & $\checkmark$ & $\checkmark$ & $\checkmark$ & $x$ & $x$ & $x$ & $\checkmark$ & $\checkmark$ & 5 \\
\hline Buerer et als & $\checkmark$ & $\checkmark$ & $\checkmark$ & $x$ & $x$ & $x$ & $\checkmark$ & $x$ & 4 \\
\hline Burn et al ${ }^{10}$ & $\checkmark$ & $\checkmark$ & $x$ & $x$ & $x$ & $x$ & $x$ & $\checkmark$ & 3 \\
\hline Cho et al26 & $x$ & $x$ & $\checkmark$ & $x$ & $x$ & $x$ & $\checkmark$ & $\checkmark$ & 3 \\
\hline Cho et ala & $\checkmark$ & $\checkmark$ & $\checkmark$ & $x$ & $x$ & $x$ & $\checkmark$ & $\checkmark$ & 5 \\
\hline Cho et alse & $\checkmark$ & $\checkmark$ & $\checkmark$ & $x$ & $x$ & $x$ & $\checkmark$ & $\checkmark$ & 5 \\
\hline Cho et als & $x$ & $x$ & $\checkmark$ & $x$ & $x$ & $x$ & $\checkmark$ & $\checkmark$ & 3 \\
\hline Evans et al ${ }^{28}$ & $\checkmark$ & $\checkmark$ & $x$ & $x$ & $x$ & $x$ & $\checkmark$ & $\checkmark$ & 4 \\
\hline Giannini et al15 & $\checkmark$ & $\checkmark$ & $\checkmark$ & $x$ & $x$ & $x$ & $\checkmark$ & $\checkmark$ & 5 \\
\hline Gould et a|29 & $x$ & $x$ & $x$ & $x$ & $x$ & $x$ & $x$ & $\checkmark$ & 1 \\
\hline Hamilton et a a ${ }^{10}$ & $x$ & $\checkmark$ & $x$ & $x$ & $x$ & $x$ & $x$ & $x$ & 1 \\
\hline Iwao et a|11 & $\mathrm{x}$ & $\mathrm{x}$ & $\mathrm{x}$ & $\mathrm{x}$ & $x$ & $\mathrm{x}$ & $x$ & $\mathrm{x}$ & 0 \\
\hline Jarvela et a $\left.\right|^{132}$ & $\checkmark$ & $\checkmark$ & $\checkmark$ & $x$ & $x$ & $x$ & $\checkmark$ & $\checkmark$ & 5 \\
\hline Jaskulka et a| & $x$ & $\checkmark$ & $\checkmark$ & $x$ & $x$ & $x$ & $\checkmark$ & $\checkmark$ & 4 \\
\hline Jeong et a|34 & $\checkmark$ & $\checkmark$ & $\checkmark$ & $x$ & $x$ & $x$ & $\checkmark$ & $\checkmark$ & 5 \\
\hline Karlsson et a $\left.\right|^{135}$ & $x$ & $\checkmark$ & $x$ & $x$ & $x$ & $x$ & $\checkmark$ & $\checkmark$ & 2 \\
\hline Karlsson et al36 & $\checkmark$ & $\checkmark$ & $x$ & $x$ & $x$ & $x$ & $\checkmark$ & $\checkmark$ & 4 \\
\hline Karlsson et a ${ }^{137}$ & $x$ & $\checkmark$ & $\checkmark$ & $x$ & $x$ & $x$ & $\checkmark$ & $\checkmark$ & 4 \\
\hline Karlsson et al $\left.\right|^{138}$ & $x$ & $\checkmark$ & $\checkmark$ & $x$ & $x$ & $x$ & $\checkmark$ & $\checkmark$ & 4 \\
\hline Keller et al $\left.\right|^{39}$ & $x$ & $\checkmark$ & $\checkmark$ & $x$ & $x$ & $x$ & $\checkmark$ & $\checkmark$ & 4 \\
\hline $\begin{array}{l}\text { Lofvenberg et } \\
\text { alat }\end{array}$ & $x$ & $\checkmark$ & $\checkmark$ & $x$ & $x$ & $\mathrm{x}$ & $\checkmark$ & $v$ & 4 \\
\hline Matsui et ala1 & $\checkmark$ & $\checkmark$ & $x$ & $\mathrm{x}$ & $x$ & $\mathrm{x}$ & $\mathrm{x}$ & $\checkmark$ & 3 \\
\hline Messer et alat2 & $\checkmark$ & $\checkmark$ & $\mathrm{x}$ & $x$ & $x$ & $x$ & $\checkmark$ & $\checkmark$ & 4 \\
\hline $\begin{array}{c}\text { Mivamoto et } \\
\text { al16 }\end{array}$ & $\checkmark$ & $\checkmark$ & $\checkmark$ & $x$ & $x$ & $x$ & $\checkmark$ & $\checkmark$ & 5 \\
\hline Nakata et a| ${ }^{17}$ & $\checkmark$ & v & $\checkmark$ & $x$ & $x$ & $x$ & $\checkmark$ & $\checkmark$ & 5 \\
\hline Park et al ${ }^{18}$ & $\checkmark$ & $\checkmark$ & $\checkmark$ & $x$ & $x$ & $x$ & $\checkmark$ & $\checkmark$ & 5 \\
\hline Petrera et al a $^{13}$ & $v$ & $\checkmark$ & $\checkmark$ & $x$ & $x$ & $x$ & $x$ & $\checkmark$ & 4 \\
\hline Porter et ala4 & $\checkmark$ & $\checkmark$ & $\checkmark$ & $x$ & $x$ & $x$ & $\checkmark$ & $\checkmark$ & 5 \\
\hline Russo et alas & $\checkmark$ & $\checkmark$ & $\checkmark$ & $x$ & $x$ & $x$ & $\checkmark$ & $\checkmark$ & 5 \\
\hline Sammarco et al ${ }^{4}$ & $x$ & $\checkmark$ & $\checkmark$ & $x$ & $x$ & $x$ & $x$ & $\checkmark$ & 3 \\
\hline $\begin{array}{c}\text { Saragaglia et } \\
\text { a|l|46 }\end{array}$ & $\checkmark$ & $\checkmark$ & $x$ & $x$ & $x$ & $x$ & $\checkmark$ & $x$ & 3 \\
\hline Schmidt et al ${ }^{2}$ & $x$ & $x$ & $\checkmark$ & $x$ & $x$ & $x$ & $\checkmark$ & $\checkmark$ & 3 \\
\hline Trichine et aly & $x$ & $\checkmark$ & $\checkmark$ & $x$ & $x$ & $x$ & $\checkmark$ & $\checkmark$ & 4 \\
\hline Ventura et al23 & $\checkmark$ & $\checkmark$ & $\checkmark$ & $x$ & $x$ & $x$ & $\checkmark$ & $\checkmark$ & 5 \\
\hline Wang, B et al'19 & $\checkmark$ & $\checkmark$ & $\checkmark$ & $x$ & $x$ & $x$ & $\checkmark$ & $\checkmark$ & 5 \\
\hline Wang, Wet al120 & $x$ & $\checkmark$ & $\checkmark$ & $x$ & $x$ & $x$ & $\checkmark$ & $\checkmark$ & 4 \\
\hline Xuet a 150 & $\checkmark$ & $\checkmark$ & $\checkmark$ & $x$ & $x$ & $x$ & $\checkmark$ & $\checkmark$ & 5 \\
\hline Xu et als & $x$ & $\checkmark$ & $\checkmark$ & $x$ & $x$ & $x$ & $\checkmark$ & $\checkmark$ & 4 \\
\hline Youn et al12 & $\checkmark$ & $\checkmark$ & $\checkmark$ & $x$ & $x$ & $x$ & $\checkmark$ & $\checkmark$ & 5 \\
\hline
\end{tabular}

Fig 3. The risk of bias present in each article used in the review. 
Fig 4. The authors' quality of bias assessment used in the review.

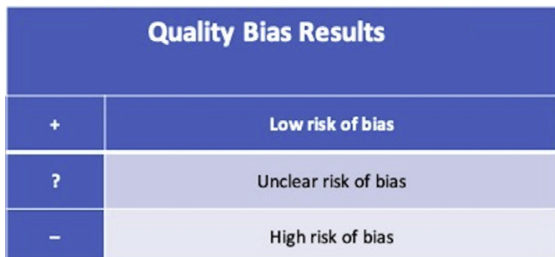

\begin{tabular}{|c|}
\hline Agoropoulos et al22 \\
\hline Algherns et al \\
\hline Brodsky et al \\
\hline
\end{tabular}

Brodsky et al ${ }^{5}$

Buerer et a ${ }^{8}$

Burn et a| ${ }^{10}$

Cho et a $\left.\right|^{24}$

Cho et a ${ }^{25}$

Evans et a ${ }^{26}$

Gould et a ${ }^{27}$

Hamilton et $\mathrm{a}^{28}$

Iwao et al ${ }^{29}$

Jarvela et $\mathrm{a}^{\mathrm{\beta 0}}$

Jaskulka et al ${ }^{\beta 1}$

Jeong et $a^{32}$

Karlsson et $\mathrm{a}^{\mathbf{3}}$

Karlsson et $\mathrm{a}^{34}$

Karlsson et $\mathbf{a}^{\mathbf{3 5}}$

Karlsson et $\mathrm{a}^{\mathrm{\beta 6}}$

Keller et a ${ }^{37}$

Lofvenberg et $a^{38}$

Matsui et a ${ }^{39}$

Messer et al ${ }^{40}$

Petrera et al ${ }^{41}$

Porter et a ${ }^{42}$

Russo et a ${ }^{43}$

Saragaglia et a a $^{44}$

Schmidt et al ${ }^{2}$

Trichine et al ${ }^{45}$

Gould et al ${ }^{27}$

\begin{tabular}{|c|}
\hline Cho et a ${ }^{46}$ \\
\hline Cho et al ${ }^{47}$ \\
\hline Porter et al $\left.\right|^{42}$ \\
\hline
\end{tabular}

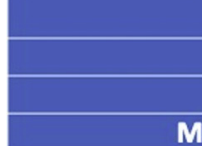

Cho et a ${ }^{46}$

Lee et $a^{20}$

Miyamoto et al ${ }^{14}$

Nakata et al ${ }^{15}$

Park et a $\left.\right|^{16}$

Sammarco et al ${ }^{4}$

Ventura et a ${ }^{21}$

Wang, B et a ${ }^{17}$

Wang, $W$ et al $^{18}$

$X u$ et al ${ }^{6}$

Youn et a $\left.\right|^{19}$

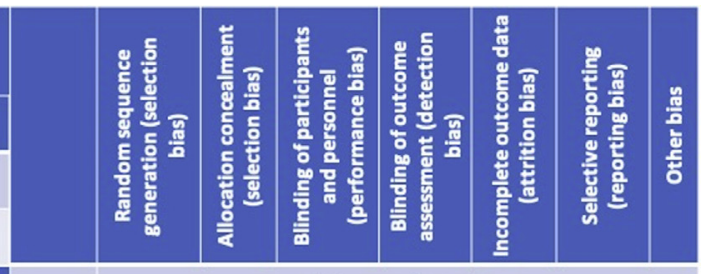

Primary Repair

1997

1989

2005

2013

2013

2012

2015

1984

1980

1993

2014

2002

1988

2016

1988

1989

1995

1999

1996

1994

2016

2000

2014

2019

2016

1997

2004

2017

1980

2015

2017

2019

2015

2017

2014

2000

2016

1999

2018

2013

2017

2014

2012
Suture Tape Augmentation

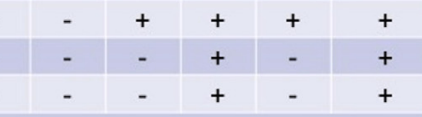

Graft Reconstruction

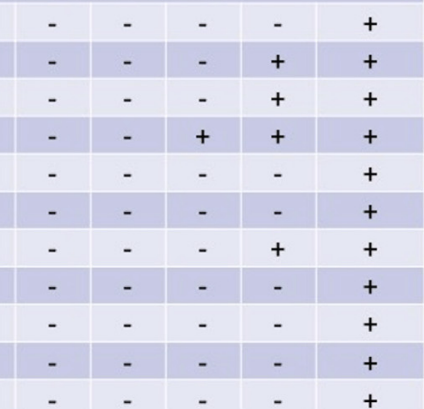




\begin{tabular}{|c|c|}
\hline Domains & Leading explanatory questions \\
\hline Selection & $\begin{array}{l}\text { 1. Does the patient(s) represent(s) the whole experience of the investigator (center) or is the selection } \\
\text { method unclear to the extent that other patients with similar presentation may not have been reported? }\end{array}$ \\
\hline \multirow{2}{*}{ Ascertainment } & 2. Was the exposure adequately ascertained? \\
\hline & 3. Was the outcome adequately ascertained? \\
\hline \multirow{3}{*}{ Causality } & 4. Were other alternative causes that may explain the observation ruled out? \\
\hline & 5. Was there a challenge/rechallenge phenomenon? \\
\hline & 6. Was there a dose-response effect? \\
\hline Reporting & 7. Was follow-up long enough for outcomes to occur? \\
\hline
\end{tabular}

Fig 5. Questions used in Figure 4 for our quality of bias assessment.

The age range was similar across operative techniques: for the GR group, it was 20.2 to 32.8 years; PR was 21.5 to 33.9 ; STA was 26.1 to 29.5 years.

\section{Quality Bias Assessment}

Risk of bias results can be found in Figure 3. Our literature review showed only 2 studies with level 1 evidence. ${ }^{24,42}$ Further, only 8 studies randomized their patient cohorts. ${ }^{14,19,24,26,30,36,42,45}$ Porter et al. ${ }^{44}$ randomized their cohort and compared outcomes between PR and STA and demonstrated a low risk for bias. However, the majority of studies were case series. Thus, due to this high risk of bias, no formal meta-analysis was able to be performed.

To evaluate the quality of bias in the papers included in our study, the Grading of Recommendations, Assessment, Development, and Evaluation (GRADE) approach was used. The Quality of Bias assessment can be found in Figure 4. This approach uses 8 parameters to evaluate the quality of bias in case reports/series, and a score between 0 and 8 is given. It is tough to solely rely on the aggregate score to determine the quality of the study because some questions have more of an impact on the quality of the paper than others. Therefore, it is recommended that the reader determine which question(s) play a more important role for their research process and look at the value of said questions for the papers. Also, questions 4, 5, and 6 are mostly relevant to case series looking at adverse drug events, which is why all of the studies included here have a value of 0 for those questions. Each leading explanatory question is listed at the bottom of Figure 5.

\section{Pre- and Postoperative Assessments}

\section{Functional Outcomes (AOFAS and Karlsson)}

AOFAS were reported for 374 participants from 11 studies, $6,13,16-18,20,21,32,43,45 \quad 183$ in the GR group, ${ }^{6,13,16-18,20,21} 166$ in $\mathrm{PR}^{21,32,43,45}$ and 25 in the STA group ${ }^{48}$ (Table 3). Postoperative AOFAS ranged from 89.0 to 95.1 for GR, 90.0 to 98.8 for PR, and 97.5 for STA. GR, PR, and STA saw improvements in their AOFAS scores. Postoperative-preoperative differences ranged from 24.0 to 34.6 for GR, from 20.1 to 38.0 for
PR, and 29.3 for STA. Two studies ${ }^{13,21}$ compared GR with PR; none found a significant difference between postoperative AOFAS scores. One study ${ }^{6}$ compared PR with STA and did not find a significant difference in preoperative or postoperative AOFAS scores.

Karlsson scores were reported for 240 participants from 8 studies. ${ }^{14,18-21,24,25,45}$ There were 118 participants from 5 studies in the GR group ${ }^{14,16,18-21}$ and 122 participants from 4 studies in the PR group. ${ }^{21,24,25,45}$ Postoperative scores ranged from 80.9 to 94.4 for GR and from 89.2 to 94.1 for PR. Both groups saw improvements: postoperative-preoperative differences ranged from 26.4 to 40.1 for GR and from 16.7 to 48.7 for PR. Ventura et al. ${ }^{23}$ compared GR with PR and found no significant difference between the 2 groups in terms of Karlsson scores. Further, none of the analyzed studies reported Karlsson scores for the STA group.

\section{Radiographic Outcomes (Anterior Drawer and Talar Tilt)}

Anterior drawer measurements were reported in 21 studies for a total of 670 participants (Table 4). There were 163 patients in the GR group, ${ }^{14-21} 420$ patients in the PR group, $2,21,24,25,30,32,39,40,44,45,46,48$ and 87 in the STA group. ${ }^{7,47}$ Anterior drawer postoperative scores ranged from 1.4 to $7.2 \mathrm{~mm}$ for GR, 2.7 to $8.6 \mathrm{~mm}$ for $\mathrm{PR}$, and 2.9 to $4.2 \mathrm{~mm}$ for STA. All groups saw improvements: preop-postoperative scores ranged from 2.9 to $7.7 \mathrm{~mm}$ for GR, 1.7 to $9.2 \mathrm{~mm}$ for PR, and 7.9 to $9.3 \mathrm{~mm}$ for STA. Ventura et al. ${ }^{21}$ compared GR with PR and found the PR group to have increased stability, as measured by anterior drawer: $1.4 \mathrm{~mm} \mathrm{(0.9)}$ for PR compared with $5.7 \mathrm{~mm}(1.1)$ for GR, $P<.01$. Xu et al. ${ }^{6}$ compared PR with STA and found no significant difference in the 2 groups in the anterior drawer outcomes.

Talar tilt was measured in 21 studies $6,7,14-21,24,29,32,35,36,39,40,44-47$ and were reported in 706 participants: 231 for 8 GR studies, ${ }^{6,14-21} 388$ for 12 PR studies, 2,21,24,32,35,36,39,40,44-46 and 87 for 3 STA studies. ${ }^{7,47}$ Postoperative talar tilt values were as follows: $2.4-7.3^{\circ}$ for $\mathrm{GR}, 1.9-6.0^{\circ}$ for $\mathrm{PR}$, and $2.4-4.5^{\circ}$ for STA. Weighted mean differences, preoperative-postoperative, for each technique were 
Table 3. Functional Outcomes Measured Pre- and Postsurgery, by Study

\begin{tabular}{|c|c|c|c|c|c|c|c|c|c|}
\hline \multirow[b]{2}{*}{ Author } & \multirow[b]{2}{*}{ Year } & \multirow[b]{2}{*}{$\mathrm{N}$} & \multirow[b]{2}{*}{ Graft Type } & \multicolumn{2}{|c|}{ AOFAS } & \multirow[b]{2}{*}{ Difference } & \multicolumn{2}{|c|}{ Karlsson } & \multirow[b]{2}{*}{ Difference } \\
\hline & & & & Preoperative* & Postoperative & & Preoperative & Postoperative & \\
\hline \multicolumn{10}{|l|}{ Graft reconstruction } \\
\hline Giannini et al. ${ }^{15}$ & 2014 & 21 & Auto- plantar gracilis. Allo-peroneus brevis & $\mathrm{n} / \mathrm{a}$ & $92.5(6.3)$ & $\mathrm{n} / \mathrm{a}$ & $\mathrm{n} / \mathrm{a}$ & $\mathrm{n} / \mathrm{a}$ & $\mathrm{n} / \mathrm{a}$ \\
\hline \multicolumn{10}{|l|}{ Autograft } \\
\hline Miyamoto et al. ${ }^{16}$ (immobilized group) & 2014 & 15 & Gracilis & $\mathrm{n} / \mathrm{a}$ & $\mathrm{n} / \mathrm{a}$ & $\mathrm{n} / \mathrm{a}$ & $62.3(4.7)$ & $94.4(7.1)$ & 32.1 \\
\hline Miyamoto et al. ${ }^{16}$ (accelerated group) & 2014 & 20 & Gracilis & $\mathrm{n} / \mathrm{a}$ & $\mathrm{n} / \mathrm{a}$ & $\mathrm{n} / \mathrm{a}$ & $64.1(4.8)$ & $91.7(7.7)$ & 27.6 \\
\hline Park et al. ${ }^{18}$ & 2016 & 30 & Peroneus longus & 57.2 & 89.0 & 31.8 & 66.9 & 93.3 & 26.4 \\
\hline Ventura et al. ${ }^{23}$ & 2018 & 20 & Peroneus Brevis & $60.2(10.2)$ & $90.1(8.2)$ & 29.9 & $59.8(9.2)$ & $92.1(8.7)$ & 32.3 \\
\hline Wang et al. ${ }^{19}$ & 2013 & 25 & Semitendinosus & 71.1 & 95.1 & 24.0 & $\mathrm{n} / \mathrm{a}$ & $\mathrm{n} / \mathrm{a}$ & $\mathrm{n} / \mathrm{a}$ \\
\hline Xu et al. ${ }^{6}$ & 2014 & 32 & Semitendinosus & $62.3(8.2)$ & $95.1(7.5)$ & 32.8 & $\mathrm{n} / \mathrm{a}$ & $\mathrm{n} / \mathrm{a}$ & $\mathrm{n} / \mathrm{a}$ \\
\hline \multicolumn{10}{|l|}{ Allograft } \\
\hline Wang et al. ${ }^{20}$ & 2017 & 19 & Semitendinosus & 64.0 & 90.3 & 26.3 & 50.8 & 90.9 & 40.1 \\
\hline Xu et al. ${ }^{6}$ & 2014 & 36 & Unspecified & $60.2(8.4)$ & $94.8(5.5)$ & 34.6 & $\mathrm{n} / \mathrm{a}$ & $\mathrm{n} / \mathrm{a}$ & $\mathrm{n} / \mathrm{a}$ \\
\hline Youn et al. ${ }^{21}$ & 2012 & 14 & Semitendinosus & $\mathrm{n} / \mathrm{a}$ & $\mathrm{n} / \mathrm{a}$ & $\mathrm{n} / \mathrm{a}$ & 54.2 & 80.9 & 26.7 \\
\hline \multicolumn{10}{|l|}{ Primary repair } \\
\hline Cho et al. ${ }^{26}$ (suture anchor group) & 2012 & 20 & & $\mathrm{n} / \mathrm{a}$ & $\mathrm{n} / \mathrm{a}$ & $\mathrm{n} / \mathrm{a}$ & $46.4(7.96)$ & $90.8(6.15)$ & 44.4 \\
\hline Cho et al. ${ }^{26}$ (transosseous suture group) & 2012 & 20 & & $\mathrm{n} / \mathrm{a}$ & $\mathrm{n} / \mathrm{a}$ & $\mathrm{n} / \mathrm{a}$ & $44.5(7.19)$ & $89.2(6.44)$ & 44.7 \\
\hline Cho et al. ${ }^{27}$ & 2015 & 24 & & $\mathrm{n} / \mathrm{a}$ & $\mathrm{n} / \mathrm{a}$ & $\mathrm{n} / \mathrm{a}$ & $43.5(\mathrm{n} / \mathrm{a})$ & $92.2(\mathrm{n} / \mathrm{a})$ & 48.7 \\
\hline Giannini et al. ${ }^{15}$ & 2014 & 17 & & $\mathrm{n} / \mathrm{a}$ & $91.8(5.2)$ & $\mathrm{n} / \mathrm{a}$ & $\mathrm{n} / \mathrm{a}$ & $\mathrm{n} / \mathrm{a}$ & $\mathrm{n} / \mathrm{a}$ \\
\hline Jeong et al. ${ }^{34}$ (stress + group) & 2016 & 35 & & $65.1(14.6)$ & $90.0(6.4)$ & 24.9 & $\mathrm{n} / \mathrm{a}$ & $\mathrm{n} / \mathrm{a}$ & $\mathrm{n} / \mathrm{a}$ \\
\hline Jeong et al. ${ }^{34}$ (stress - group) & 2016 & 10 & & $72.5(9.3)$ & $92.6(7.8)$ & 20.1 & $\mathrm{n} / \mathrm{a}$ & $\mathrm{n} / \mathrm{a}$ & $\mathrm{n} / \mathrm{a}$ \\
\hline Russo et al. ${ }^{45}$ & 2016 & 18 & & $67.6(\mathrm{n} / \mathrm{a})$ & $98.9(\mathrm{n} / \mathrm{a})$ & 31.2 & $\mathrm{n} / \mathrm{a}$ & $\mathrm{n} / \mathrm{a}$ & $\mathrm{n} / \mathrm{a}$ \\
\hline Trichine et al. ${ }^{47}$ & 2017 & 38 & & $57.0(\mathrm{n} / \mathrm{a})$ & $95.0(\mathrm{n} / \mathrm{a})$ & 38.0 & $75.5(\mathrm{n} / \mathrm{a})$ & $92.2(\mathrm{n} / \mathrm{a})$ & 16.7 \\
\hline Ventura et al. ${ }^{23}$ & 2018 & 20 & & $60.9(8.1)$ & $91.4(6.9)$ & 30.5 & $62.5(10.1)$ & $94.1(7.4)$ & 31.6 \\
\hline Xu et al. ${ }^{6}$ & 2019 & 28 & & $67.3(10.6)$ & $96.3(6.0)$ & 29 & $\mathrm{n} / \mathrm{a}$ & $\mathrm{n} / \mathrm{a}$ & $\mathrm{n} / \mathrm{a}$ \\
\hline \multicolumn{10}{|l|}{ Suture tape augmentation } \\
\hline Xu et al. ${ }^{6}$ & 2019 & 25 & & $68.2(9.5)$ & $97.5(3.3)$ & 29.3 & $\mathrm{n} / \mathrm{a}$ & $\mathrm{n} / \mathrm{a}$ & $\mathrm{n} / \mathrm{a}$ \\
\hline
\end{tabular}

n/a, not available.

*All values are reported as mean (standard deviation). 
Table 4. Radiographic Outcomes Measured Pre- and Postsurgery, by Study

\begin{tabular}{|c|c|c|c|c|c|c|c|c|c|}
\hline \multirow[b]{2}{*}{ Author } & \multirow[b]{2}{*}{ Year } & \multirow[b]{2}{*}{$\mathrm{N}$} & \multirow[b]{2}{*}{ Graft Type } & \multicolumn{2}{|c|}{ Anterior Drawer, mm } & \multirow[b]{2}{*}{ Difference } & \multicolumn{2}{|c|}{ Talar Tilt, $^{\circ}$} & \multirow[b]{2}{*}{ Difference } \\
\hline & & & & Preoperative* & Postoperative & & Preoperative & Postoperative & \\
\hline \multicolumn{10}{|l|}{ Graft reconstruction } \\
\hline \multicolumn{10}{|l|}{ Autograft } \\
\hline Miyamoto et al. ${ }^{16}$ (immobilized group) & 2014 & 15 & Gracilis & $7.7(1.8)$ & $4.0(1.6)$ & 3.7 & $8.7(2.6)$ & $3.8(1.5)$ & 4.9 \\
\hline Miyamoto et al. ${ }^{16}$ (accelerated group) & 2014 & 20 & Gracilis & $8.7(2.1)$ & $4.3(1.2)$ & 4.4 & $10.5(3.4)$ & $4.3(1.8)$ & 6.2 \\
\hline Park et al. ${ }^{18}$ & 2016 & 30 & Peroneus Longus & $10.2(3.3)$ & $6.3(1.9)$ & 3.9 & $15.3(6.2)$ & $3.4(3.0$ & 11.9 \\
\hline Ventura et al. ${ }^{23}$ & 2018 & 20 & Peroneus Brevis & $7.8(1.5)$ & $1.4(0.9)$ & 6.4 & $11.9(2.4)$ & $2.4(2.1)$ & 9.5 \\
\hline Wang et al. ${ }^{19}$ & 2013 & 25 & Semitendinosus & $12.3(3.0)$ & $4.6(1.8)$ & 7.7 & $14.0(3.7)$ & $3.8(1.8)$ & 10.2 \\
\hline Xu et al. ${ }^{6}$ & 2014 & 32 & Semitendinosus & (n/a) & (n/a) & $(\mathrm{n} / \mathrm{a})$ & $14.0(3.2)$ & $3.8(1.2)$ & 10.2 \\
\hline \multicolumn{10}{|l|}{ Allograft } \\
\hline Nakata et al. ${ }^{17}$ & 2000 & 20 & Fascia lata & $9.2(3.9)$ & $4.4(2.5)$ & 4.8 & $12.3(4.2)$ & $5.9(3.0)$ & 6.4 \\
\hline Wang et al. ${ }^{20}$ & 2017 & 19 & Semitendinosus & $9.8(1.0)$ & $4.0(1.0)$ & 5.8 & $17.3(3.6)$ & $4.2(1.1)$ & 13.2 \\
\hline $\mathrm{Xu}$ et al. $^{6}$ & 2014 & 36 & Unspecified & (n/a) & (n/a) & $(\mathrm{n} / \mathrm{a})$ & $13.0(3.5)$ & $3.6(1.4)$ & 9.4 \\
\hline Youn et al. ${ }^{21}$ & 2012 & 14 & Semitendinosus & $10.1(3.3)$ & $7.2(2.7)$ & 2.9 & $15.5(4.4)$ & $7.3(3.6)$ & 8.2 \\
\hline \multicolumn{10}{|l|}{ Primary repair } \\
\hline Cho et al. ${ }^{26}$ (suture anchor group) & 2012 & 20 & & $8.2(1.9)$ & $4.2(1.1)$ & 4.0 & $17.2(4.9)$ & $5.9(2.5)$ & 11.3 \\
\hline Cho et al. ${ }^{26}$ (transosseous suture group) & 2012 & 20 & & $8.4(2.3)$ & $4.1(1.2)$ & 4.3 & $15.8(5.1)$ & $5.4(1.9)$ & 10.4 \\
\hline Cho et al. ${ }^{27}$ & 2015 & 24 & & $13.3(\mathrm{n} / \mathrm{a})$ & $4.8(\mathrm{n} / \mathrm{a})$ & 8.5 & $15.4(\mathrm{n} / \mathrm{a})$ & $4.9(\mathrm{n} / \mathrm{a})$ & 10.5 \\
\hline Jarvela et al..$^{32}$ (anatomic reconstruction) & 2002 & 15 & & $10.3(1.3)$ & $8.6(2.4)$ & 1.7 & $\mathrm{n} / \mathrm{a}$ & $\mathrm{n} / \mathrm{a}$ & $\mathrm{n} / \mathrm{a}$ \\
\hline Jarvela et al. ${ }^{32}$ (primary repair) & 2002 & 17 & & $11.9(2.1)$ & $8.0(1.8)$ & 3.9 & $\mathrm{n} / \mathrm{a}$ & $\mathrm{n} / \mathrm{a}$ & $\mathrm{n} / \mathrm{a}$ \\
\hline Jeong et al. ${ }^{34}$ (stress +$)$ & 2016 & 35 & & $7.0(2.2)$ & $5.1(7.7)$ & 1.9 & $14.4(4.2)$ & $5.4(3.4)$ & 9.0 \\
\hline Jeong et al. $^{34}$ (stress -) & 2016 & 10 & & $6.6(1.4)$ & $4.7(2.7)$ & 1.9 & $4.8(2.6)$ & $3.0(1.5)$ & 1.8 \\
\hline Karlsson et al..$^{38}$ DM (I) & 1995 & 20 & & $10.2(\mathrm{n} / \mathrm{a})$ & $7.2(\mathrm{n} / \mathrm{a})$ & 3.0 & $9.5(\mathrm{n} / \mathrm{a})$ & $4.2(\mathrm{n} / \mathrm{a})$ & 5.3 \\
\hline Karlsson et al. ${ }^{38}$ EM (II) & 1995 & 20 & & $10.7(\mathrm{n} / \mathrm{a})$ & $6.7(\mathrm{n} / \mathrm{a})$ & 4.0 & $8.8(\mathrm{n} / \mathrm{a})$ & $3.7(\mathrm{n} / \mathrm{a})$ & 5.1 \\
\hline Karlsson et al. ${ }^{37}$ DM (A) & 1999 & 15 & & $11.0(\mathrm{n} / \mathrm{a})$ & $6.5(\mathrm{n} / \mathrm{a})$ & 4.5 & $10.0(\mathrm{n} / \mathrm{a})$ & $4.0(\mathrm{n} / \mathrm{a})$ & 6.0 \\
\hline Karlsson et al. ${ }^{37}$ EM (B) & 1999 & 15 & & $10.5(\mathrm{n} / \mathrm{a})$ & $5.0(\mathrm{n} / \mathrm{a})$ & 5.5 & $9.0(\mathrm{n} / \mathrm{a})$ & $4.0(\mathrm{n} / \mathrm{a})$ & 5.0 \\
\hline Matsui et al. ${ }^{41}$ (open technique) & 2016 & 18 & & $8.4(\mathrm{n} / \mathrm{a})$ & $3.2(\mathrm{n} / \mathrm{a})$ & 5.2 & $10.0(\mathrm{n} / \mathrm{a})$ & $3.2(\mathrm{n} / \mathrm{a})$ & 6.8 \\
\hline Matsui et al. ${ }^{41}$ (arthroscopic) & 2016 & 19 & & $9.1(\mathrm{n} / \mathrm{a})$ & $2.9(\mathrm{n} / \mathrm{a})$ & 6.2 & $9.9(\mathrm{n} / \mathrm{a})$ & $2.9(\mathrm{n} / \mathrm{a})$ & 7.0 \\
\hline Messer et al. ${ }^{42}$ & 2000 & 22 & & $7.0(2.1)$ & $2.7(1.5)$ & 4.3 & $10.1(4.4)$ & $4.5(1.2)$ & 5.6 \\
\hline Saragaglia et al. ${ }^{46}$ & 1997 & 32 & & $8.2(\mathrm{n} / \mathrm{a})$ & $6.5(\mathrm{n} / \mathrm{a})$ & 1.7 & $14.5(\mathrm{n} / \mathrm{a})$ & $6.0(\mathrm{n} / \mathrm{a})$ & 8.5 \\
\hline Schmidt et al. ${ }^{2}$ & 2004 & 32 & & $8.9(2.0)$ & $6.9(2.6)$ & 2.0 & $10.3(4.1)$ & $5.3(3.9)$ & 5.0 \\
\hline Trichine et al. ${ }^{47}$ & 2017 & 38 & & $13.2(\mathrm{n} / \mathrm{a})$ & $4.0(\mathrm{n} / \mathrm{a})$ & 9.2 & $15.2(\mathrm{n} / \mathrm{a})$ & $3.8(\mathrm{n} / \mathrm{a})$ & 11.4 \\
\hline Ventura et al. ${ }^{23}$ & 2018 & 20 & & $8.9(1.3)$ & $5.7(1.1)$ & 3.2 & $12.2(2.3)$ & $1.9(1.4)$ & 10.8 \\
\hline Xu et al. ${ }^{6}$ & 2019 & 28 & & $12.2(3.9)$ & $3.1(1.3)$ & 9.1 & $14.2(3.5)$ & $2.7(1.4)$ & 11.5 \\
\hline \multicolumn{10}{|l|}{ Suture tape augmentation } \\
\hline Cho et al. ${ }^{48}$ & 2015 & 34 & & $12.4(5.1)$ & $4.1(2.8)$ & 8.3 & $16.3(5.4)$ & $4.5(3.5)$ & 11.8 \\
\hline Cho et al. ${ }^{49}$ & 2017 & 28 & & $12.1(5.5)$ & $4.2(2.8)$ & 7.9 & $16.2(5.1)$ & $3.6(2.2)$ & 12.6 \\
\hline $\mathrm{Xu}$ et al. ${ }^{6}$ & 2019 & 25 & & $12.2(3.6)$ & $2.9(1.6)$ & 9.3 & $14.0(3.2)$ & $2.4(1.3)$ & 11.6 \\
\hline
\end{tabular}

DM, delayed mobilization; EM, early mobilization; n/a, not available.

*All values reported as mean (standard deviation). 
Table 5. Reported Time to Return to Sports, by Study

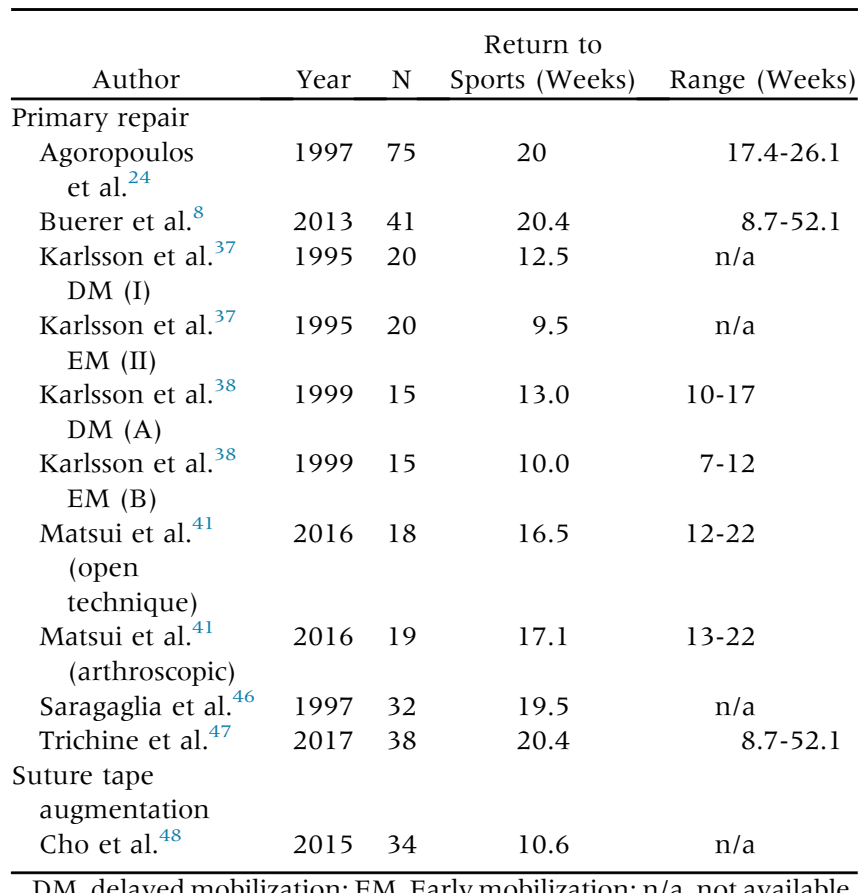

GR 4.9-13.2 ${ }^{\circ}$, PR 1.8-11.5 , and STA 11.6-12.6 ${ }^{\circ}$ Ventura et al. ${ }^{21}$ found no significant difference in talar tilt measurements between their GR and PR groups. $\mathrm{Xu}$ et al. ${ }^{6}$ found no significant difference in talar tilt measurements between their PR and STA groups.

\section{Return to Sport (RTS)}

Mean days RTS was reported in 8 studies $8,22,35,36,39,44,45,47$ and included 327 participants (Table 5). Only one study ${ }^{47}$ reported RTS for the STA technique, $\mathrm{n}=34 ; 7$ were $\mathrm{PR}, 8,22,35,36,39,44,45 \mathrm{n}=293$; none of the GR studies reported weeks to RTS in their findings. The one STA study reported RTS at 10.6 weeks. The PR group ranged from 9.5-20.4 weeks. No comparative studies used RTS as a measured outcome.

\section{Complications, Skin Wounds, Reoperation}

Complications are summarized in Table 6. When we compared the overall complication rate ranges among the 3 techniques, the GR group had an overall complication rate range of $0 \%$ to $10 \%$, PR had $0 \%$ to $23.1 \%$, and STA was $2.9 \%$ to $17.9 \%$. GR reported a skin wound rate range of $0 \%$, whereas $\mathrm{PR}$ reported $0 \%$ to $8.1 \%$, and STA reported $0 \%$ to $9.1 \%$. Range of rates of reoperation for GR was $0 \%$, PR $0 \%$ to $8 \%$, and STA $0 \%$ to $2.9 \%$.

Among the comparative studies, Giannini et al. ${ }^{15}$ and Ventura et al. ${ }^{21}$ reported no complications in either their GR group or PR group. Porter et al. ${ }^{42}$ compared PR with STA. They reported $8 \%$ complications in PR group compared with $13.6 \%$ in STA $(2 / 25$ vs $3 / 22$, respectively). They had $4 \%$ skin wounds in PR compared with $9.1 \%$ in STA (1/25 vs 2/22). They had $8 \%(2 / 25)$ reoperation rate for the PR group compared with 0 for the STA group. Xu et al. ${ }^{6}$ also compared PR with STA and reported $7.1 \%(2 / 28)$ complications in PR compared with $12 \%$ (3/28) in STA. They had $3.6 \%(1 / 28)$ skin wounds in PR compared with $0 \%$ in STA. Finally, they had a $3.6 \%$ (1/28) reoperation rate for the PR group compared with $0 \%$ for the STA group.

\section{Meta-Analyses: Functional Measures}

A series of forest plots were constructed to compare SMDs on functional (Fig $6 \mathrm{~A}$ and $\mathrm{B}$ ) and radiographic measures (Fig $7 \mathrm{~A}$ and $\mathrm{B}$ ). Results for AOFAS are shown in Figure 6A; GR: 3.99, 95\% CI 3.44-4.55 versus PR: 3.24, 95\% CI 2.34-4.13 versus 4.06, 95 CI 3.065.05. Heterogeneity as measured by $\mathrm{I}^{2}$ ranged from $17 \%$ in GR to $75 \%$ in PR indicating high variability among study results. While all studies showed improvement in AOFAS (which was significant for PR), there were little differences observed by surgery type as indicated by overlapping confidence intervals for SMD. However, only one study was included in STA; therefore, the random effects model was not applicable. Moreover, it is important to note that Higgins and Thompson, 2014 report that meta-analysis of less than 10 studies may be underpowered and may not yield reliable results. Regardless, the overall estimate for the standardized effect size of AOFAS was $\mathrm{I}^{2}=69 \%$, $\mathrm{SMD}=3.81,95 \%$ CI 3.45-4.15, $P=.16$. indicating no significant improvement observed among these studies. Similar results were found among studies reporting Karlsson Scores, although STA was not applicable: $\mathrm{I}^{2}=$ $49 \%, \mathrm{SMD}=4.08,95 \%$ CI 3.72-4.45, $P=.31$.

\section{Meta-Analyses: Radiographic Measures}

Likewise, forest plots with standardized mean differences were conducted for radiographic measures. Anterior drawer measures (Fig 7A) all showed high heterogeneity among studies with significant differences observed within the 3 surgery types: GR $\mathrm{I}^{2}=89 \%$, $P<.01 ; \mathrm{PR} \mathrm{I}^{2}=91 \%, P<.01, \mathrm{STA} \mathrm{I}^{2}=75 \%, P=.02$. However, the overall effects were not significant, $\mathrm{I}^{2}=90 \%, P<.73, \mathrm{SMD}=-2.62,95 \% \mathrm{CI}-3.07$ to -2.16 . Results for talar tilt (Fig 7B) were nearly the same, $\mathrm{I}^{2}=$ $84 \%, P<.80, \mathrm{SMD}=-3.18,95 \% \mathrm{CI}-3.59$ to -2.77 .

Because $\mathrm{I}^{2}$ among the studies was almost always high, and few STA surgery type studies were included, these meta-analyses results should be reviewed with caution. Future research may want to consider meta-regression techniques to compensate for high variability among studies, while limiting comparisons to graft reconstruction versus primary repair.

\section{Discussion}

This systematic review demonstrates that all 3 surgical techniques have favorable postoperative outcomes. In 
Table 6. Complications by Operative Technique

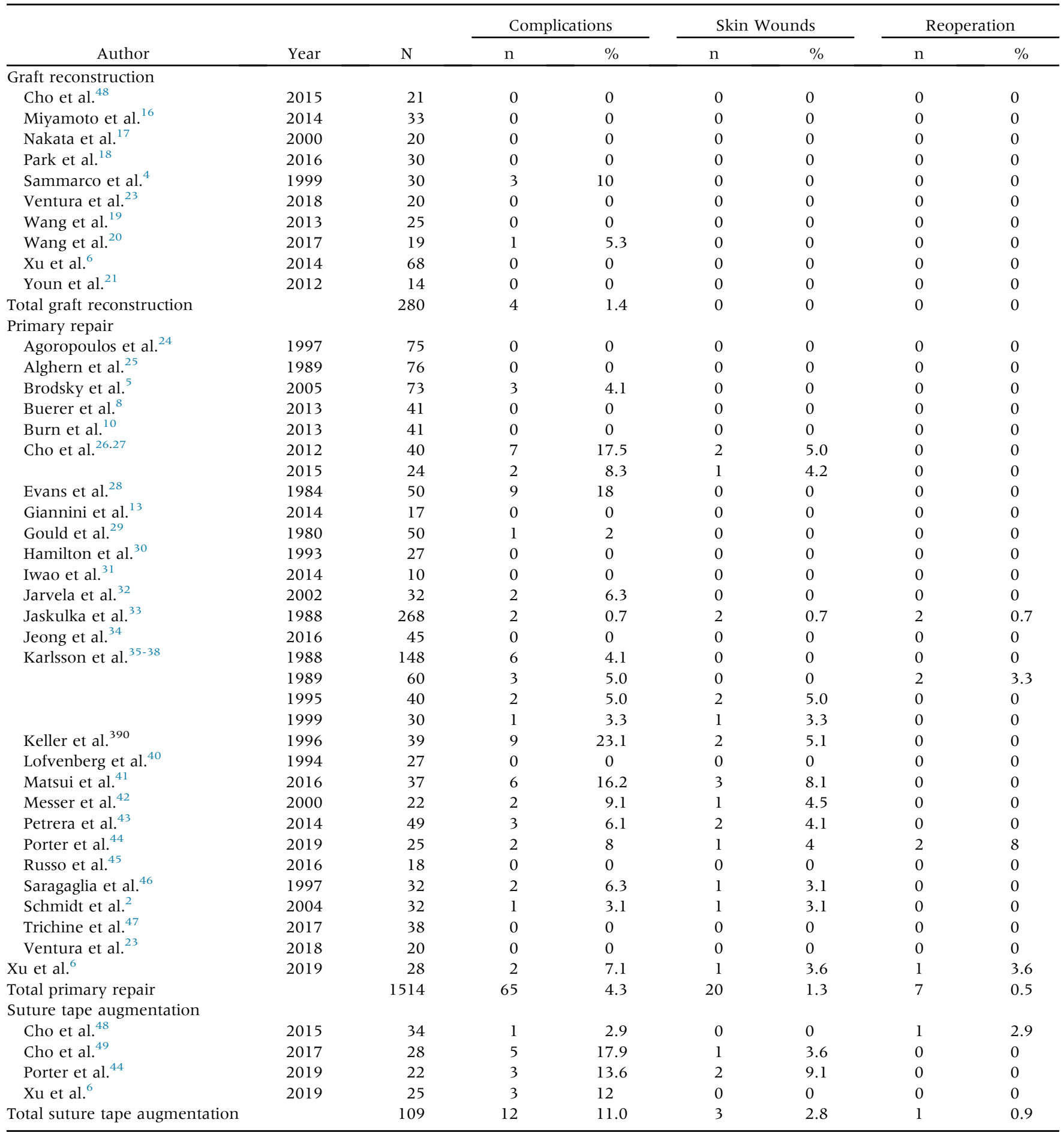

regard to PR versus GR, all studies demonstrated improvements in AOFAS and Karlsson scores, suggesting that both techniques are viable options. Among the cohort studies comparing between surgical techniques, there were no differences in functional outcomes, measured by AOFAS or Karlsson scores. ${ }^{13,21}$ The one study that compared AOFAS scores between PR and STA groups found no significant difference between preoperative and postoperative scores. ${ }^{48}$ None of the studies in the STA group used Karlsson measurements in their outcomes. When looking at radiographic outcomes (anterior drawer and talar tilt), all surgical techniques demonstrated improvement. Xu et al. ${ }^{6}$ found that there was no difference in anterior drawer or talar tilt 
A

Subgroup

Graft Reconstruction

Park et al 2016 [16]

Ventura et al 2018 [20]

Wang, B et al 2013 [17]

Wang, W et al 2017 [18]

Xu et al 2014 [6]

Xu et al 2014 [6]

Random effects model

$I^{2}=17 \%[0 \% ; 62 \%], \chi_{5}^{2}=6.01(p=0.31)$

Primary Repair

Jeong et al (Stress -) 2016 [31]

Jeong et al (Stress +) 2016 [31]

Russo et al 2016 [42]

Trichine et al 2017 [44]

Ventura et al 2018 [20]

Xu et al 2019 [47]

Random effects model

$I^{2}=75 \%[44 \% ; 89 \%], \chi_{5}^{2}=20.16(p<0.01)$

Suture Tape Augmentation

Xu et al 2019 [47]

Random effects model

not applicable mixed-effects model: pre- and postoperative measures. (B) Forest plot of our Karlsson Scores mixed-effects model pre- and postoperative measures. (AOFAS, American Orthopaedic Foot Ankle Score.)

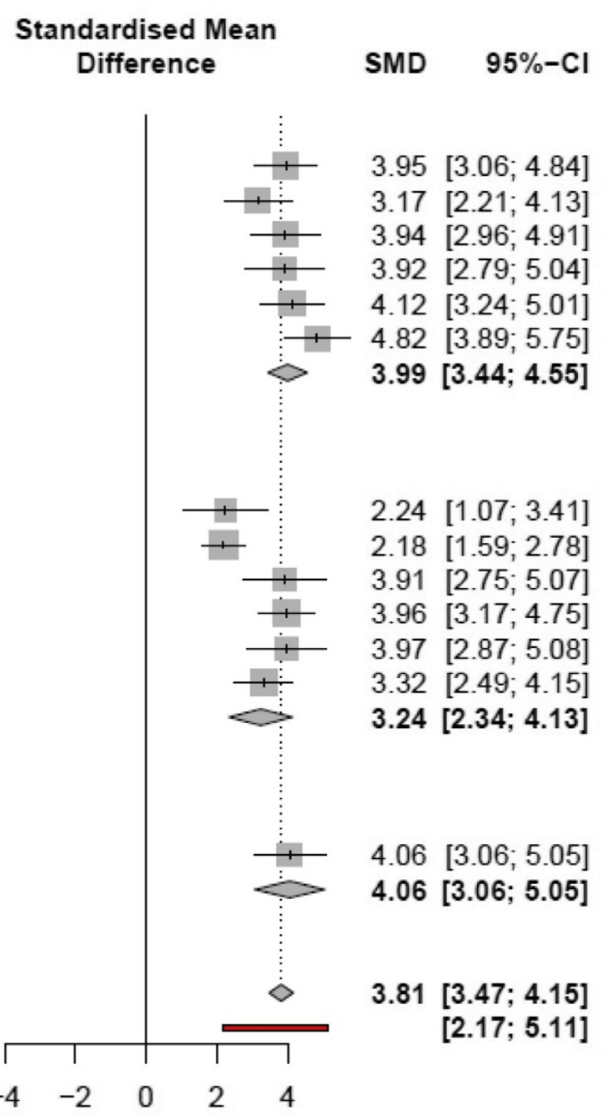

B

\section{Subgroup}

Graft Reconstruction

Miyamoto et al (Accelerated) 2014 [14]

Miyamoto et al (Immobilized) 2014 [14]

Park et al 2016 [16]

Ventura et al 2018 [20]

Wang $W$ et al 2017 [18]

Youn et al 2012 [19]

Random effects model

$I^{2}=0 \%[0 \% ; 60 \%], \chi_{5}^{2}=3.16(p=0.68)$

Primary Repair

Cho et al (Suture) 2012 [23]

Cho et al (Transosseous) 2012 [23]

Cho et al 2015 [24]

Trichine et al 2017 [44]

Ventura et al 2018 [20]

Random effects model

$I^{2}=74 \%[37 \% ; 90 \%], \chi_{4}^{2}=15.64(p<0.01)$

Fixed effects (plural) model

Prediction interval

$l^{2}=49 \%[0 \% ; 74 \%], \chi_{1}^{2}=1.04(p=0.31)$

\section{Standardised Mean} Difference

SMD $\quad 95 \%-\mathrm{Cl}$

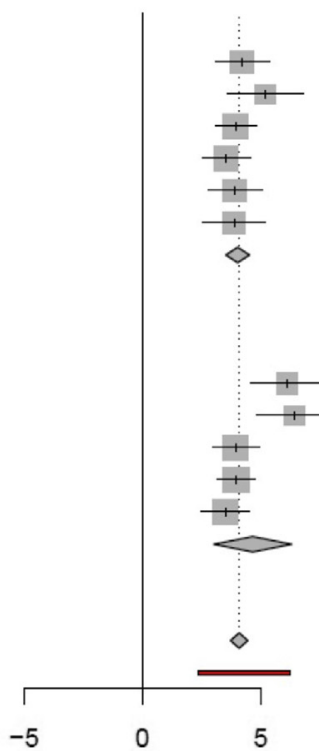

$4.22[3.06 ; 5.37]$

$5.19[3.61 ; 6.77]$

$3.95[3.06 ; 4.84]$

$3.54[2.51 ; 4.56]$

$3.92[2.79 ; 5.04]$

$3.88[2.56 ; 5.21]$

4.02 [3.52; 4.52]

$6.12[4.58 ; 7.66]$

$6.42[4.81 ; 8.02]$

$3.93[2.94 ; 4.93]$

$3.96[3.17 ; 4.75]$

$3.50[2.48 ; 4.52]$

$4.66[3.01 ; 6.31]$

4.08 [3.72; 4.45]

$[2.35 ; 6.24]$ 


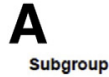

\section{Graft Reconstruction}

Miyamoto et al (Accelerated) 2014 [14] Miyamoto et al (Immobilized) 2014 [14] Nakata et al 2000 [15] Park et al 2016 [16] Ventura et al 2018 [20] Wang, B et al 2013 [17] Youn et al 2012 [19] Youn et al 2012 [19] $l^{2}=89 \%[81 \% ; 94 \%], \chi_{7}^{2}=64.68(p<0.01)$

Primary Repair

ire anchor) 2012 [23] Cho et al (Transosseous suture) 2012 [23] Cho et al 2015 [24] Jarvela et al (Anatomic reconstruction) 2002 [29] Jeong et al (Stress -) 2016 [31] Jeong et al (Stress +) 2016 [31] Karlsson et al (DM I) 1995 [34] Karlsson et al (EM II) 1995 [34] Karlsson et al (DM A) 1999 [35] Karlsson et al (EM B) 1999 [35] Matsui et al (Arthroscopic) 2016 [38] Matsui et al (Open technique) 2016 [38] Messer et al 2000 [39] Saragaglia et al 1997 [43] Schmidt et al 2004 [2] Trichine et al 2017 [44] Ventura et al $2018[20]$ Xu et al 2019 [47]

Random effects model
$l^{2}=91 \%[88 \% ; 94 \%], \chi_{18}^{2}=210.3(p<0.01)$

Suture Tape Augmentation

Cho et al 2015 [45]

Cho et al 2017 [46]

Random effects

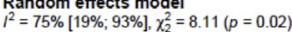

Fixed effects (plural) model

Prediction interval
$l^{2}=90 \%[87 \% ; 92 \%], \chi_{2}^{2}=0.63(p=0.73)$
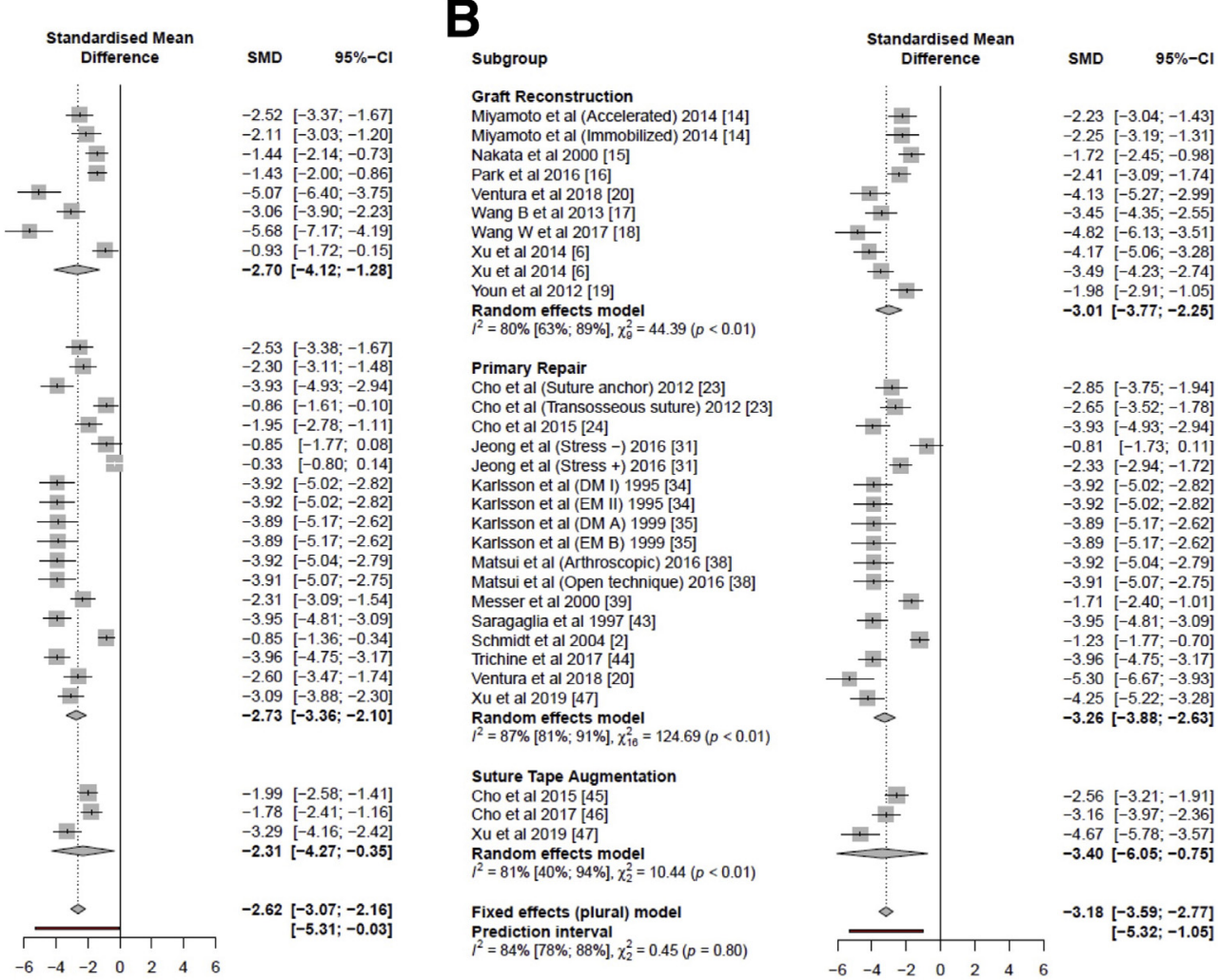

Fig 7. (A) Forest plot of our anterior drawer mixed-effects model pre- and postoperative. measures. (B) Forest plot of our talar tilt mixed-effects model pre- and postoperative measures.

outcomes between the PR and STA groups. Although Ventura et $\mathrm{al}^{2}{ }^{21}$ found that the GR technique to have increased postoperative stability, as measured by anterior drawer, they found no significant difference in talar tilt. However, currently there is no study that directly evaluates for RTS and compares STA to either PR or GR.

Porter et al. ${ }^{42}$ compared PR with STA and used the Foot and Ankle Outcome Score and Tegner score. They found STA to have statistically significant better outcomes compared with their PR group. However, we did not use either of these measurements due to their being less commonly used. This further emphasizes the necessity to have a standard measurement tool for functional ankle outcomes.

Furthermore, 2 studies $^{13,21}$ did not find any significant difference in AOFAS scores between GR and PR. These studies demonstrate results which indicate that repair and reconstruction are both effective methods for lateral ankle ligament surgery. The study conducted by Byung-Ki Cho et al. ${ }^{7}$ and colleagues using the STA demonstrated results indicating this augment is a viable technique for repair in which the Broström repair would not be optimal, such as a ligament with excessive laxity. Our study showed significant improvement in both mean talar tilt angle and anterior talar translation at final follow up. However, no current studies used radiographic outcomes to compare STA with PR or GR.
Cho et al. $^{49}$ used STA and showed that the average RTS was 10.6 weeks $(\mathrm{n}=68)$, whereas Buerer et al. ${ }^{8}$ used PR and showed an average RTS of 20.4 weeks. There were no comparative cohort studies that measured RTS. Hence, this may illustrate that STA could provide the benefit of athletes to RTS sooner than patients treated in PR. However, like we previously stated there are no current studies looking at RTS in the GR. Furthermore, more studies are needed to see if STA would provide benefit over patients treated with GR. Thus, to more definitively make recommendations on RTS, randomized controlled trials are needed.

Overall, low rates of complications were seen. No cohort study statistically analyzed differences in complication rates. Porter et al. ${ }^{42}$ did find a greater rate of complications in their STA group compared with the PR group, although it is unclear if this is statistically significant. It is plausible that comorbid conditions had a modifying role in complication rates, not solely the surgical technique. More in-depth, randomized trials would be needed to determine if complications are more common for any particular surgical technique.

Furthermore, future studies are needed with a large comparable patient population to draw any strong statistical conclusions between the differing surgical techniques available for lateral ankle ligament injuries. In addition, future studies should also determine ideal 
postoperative rehabilitation protocols for these differing techniques respectively, in particular STA due to it being a relatively newer technique. Thus, like many fields of orthopaedics, a more standardized recording of function outcomes and greater-level evidence of randomized control studies assessing these different surgical techniques are needed to justify which technique is more superior.

\section{Limitations}

Our study does contain significant limitations which must be addressed. One is the heterogenous distribution of patients analyzed among the different arms of the study (31 studies for PR vs 10 studies for GR vs 4 studies for STA). Thus, due to this heterogenous distribution and there being limited high-level evidence directly evaluating these different surgical techniques, a more formal meta-analysis was unable to be performed. Hence, further limiting our systematic review with majority of case series, which limits our conclusion drawn from this study. Also, there were varying surgical techniques within the 3 groups that also limited the ability to directly compare the three groups. For example, if lateral ankle ligament repairs were performed using differing novel techniques as well as intrinsic differences in autograft/allograft quality in the reconstruction arm. Another limitation is that outcome measures were not standardized across studies or there was a wide variety of functional outcomes reported, in which we illustrated in Figure 1, hence, decreasing the patient population available for direct comparison and limiting any meta-analysis in the future. Another limitation to this study was due to the poorly defined patient selection in patients suffering from acute versus chronic injuries. We were unable to differentiate our outcomes between acute versus chronic injuries that underwent surgeries. Thus, this could have also skewed overall final results. Finally, Karlsson and AOFAS scores were used in this analysis because they were reported the most frequently in the current literature. However, neither of these functional outcome scores have been validated for lateral ankle instability and its corresponding treatments.

\section{Conclusions}

Excellent outcomes were noted across all intervention groups. Current literature may suggest there is no difference in functional outcomes between patient's treated with PR versus GR. However, there may be a potential improvement in functional outcomes with PR versus STA.

\section{References}

1. DiGiovanni CW, Brodsky A. Current concepts: Lateral ankle instability. Foot Ankle Int 2006;27:854-866.
2. Schmidt R, Benesch S, Friemert B, Herbst A, Claes L, Gerngross H. Anatomical repair of lateral ligaments in patients with chronic ankle instability. Knee Surg Sports Traumatol Arthrosc 2005;13:231-237.

3. Sjolin SU, Dons-Jensen H, Simonsen O. Reinforced anatomical reconstruction of the anterior talofibular ligament in chronic anterolateral instability using a periosteal flap. Foot Ankle 1991;12:15-18.

4. Sammarco GJ, Idusuyi OB. Reconstruction of the lateral ankle ligaments using a split peroneus brevis tendon graft. Foot Ankle Int 1999;20:97-103.

5. Brodsky AR, O'Malley MJ, Bohne WH, Deland JA, Kennedy JG. An analysis of outcome measures following the Brostrom-Gould procedure for chronic lateral ankle instability. Foot Ankle Int 2005;26:816819.

6. Xu X, Hu M, Liu J, Zhu Y, Wang B. Minimally invasive reconstruction of the lateral ankle ligaments using semitendinosus autograft or tendon allograft. Foot Ankle Int 2014;35:1015-1021.

7. Cho BK, Park KJ, Park JK, SooHoo NF. Outcomes of the modified Brostrom procedure augmented with suturetape for ankle instability in patients with generalized ligamentous laxity. Foot Ankle Int 2017;38:405-411.

8. Buerer Y, Winkler M, Burn A, Chopra S, Crevoisier X. Evaluation of a modified Brostrom-Gould procedure for treatment of chronic lateral ankle instability: A retrospective study with critical analysis of outcome scoring. Foot Ankle Surg 2013;19:36-41.

9. Karlsson J, Peterson L. Evaluation of ankle joint function: The use of a scoring scale. Foot 1991;1:15-19.

10. Burn A, Buerer Y, Chopra S, Winkler M, Crevoisier X. Critical evaluation of outcome scales assessment of lateral ankle ligament reconstruction. Foot Ankle Int 2013;34:995-1005.

11. Kitaoka HB, Alexander IJ, Adelaar RS, Nunley JA, Myerson MS, Sanders M. Clinical rating systems for the ankle-hindfoot, midfoot, hallux, and lesser toes. Foot Ankle Int 1994;15:349-353.

12. Higgins JPT, Thomas J, Chandler J, Cumpston M, Li T, Page MJ, Welch VA, eds. Cochrane Handbook for Systematic Reviews of Interventions version 6.0 (updated July 2019). Cochrane, 2019. Www.training.cochrane.org/handbook Accessed June 2021.

13. Higgins JPT, Thompson SG. Controlling the risk of spurious findings from meta-regression. Stat Med 2004;23: 1663-1682.

14. Harrer M, Cuijpers P, Furukawa TA, Ebert DD. Doing Meta-Analysis in R: A Hands-on Guide, https://bookdown. org/MathiasHarrer/Doing_Meta_Analysis_in_R/ 2019. Accessed June 2021.

15. Giannini S, Ruffilli A, Pagliazzi G, et al. Treatment algorithm for chronic lateral ankle instability. Muscles Ligaments Tendons J 2014;4:455-460.

16. Miyamoto W, Takao M, Yamada K, Matsushita T. Accelerated versus traditional rehabilitation after anterior talofibular ligament reconstruction for chronic lateral instability of the ankle in athletes. Am J Sports Med 2014;42:1441-1447.

17. Nakata K, Shino K, Horibe S, Natsu-ume T, Mae T, Ochi T. Reconstruction of the lateral ligaments of the ankle using solvent-dried and gamma-irradiated allogeneic fascia lata. J Bone Joint Surg Br 2000;82:579-582. 
18. Park CH, Lee WC. Donor site morbidity after lateral ankle ligament reconstruction using the anterior half of the peroneus longus tendon autograft. Am J Sports Med 2017;45:922-928.

19. Wang B, Xu XY. Minimally invasive reconstruction of lateral ligaments of the ankle using semitendinosus autograft. Foot Ankle Int 2013;34:711-715.

20. Wang W, Xu GH. Allograft tendon reconstruction of the anterior talofibular ligament and calcaneofibular Ligament in the treatment of chronic ankle instability. BMC Musculoskelet Disord 2017;18:150.

21. Youn H, Kim YS, Lee J, Choi WJ, Lee JW. Percutaneous lateral ligament reconstruction with allograft for chronic lateral ankle instability. Foot Ankle Int 2012;33:99-104.

22. Lee DO, Eom JS, Jung HG. The effect of smoking on the outcomes of lateral ankle ligament reconstruction. J Orthop Sci 2018;23:88-91.

23. Ventura A, Legnani C, Corradini C, Borgo E. Lateral ligament reconstruction and augmented direct anatomical repair restore ligament laxity in patients suffering from chronic ankle instability up to 15 years from surgery. Knee Surg Sports Traumatol Arthrosc 2020;28:202-207.

24. Agoropoulos Z, Papachristou G, Efstathopoulos N, Kokoroghiannis C. Late results of surgical repair in recent ruptures of the lateral ligament of the ankle. Injury 1997;28:531-534.

25. Ahlgren $O$, Larsson S. Reconstruction for lateral ligament injuries of the ankle. J Bone Joint Surg Br 1989;71:300-303.

26. Cho BK, Kim YM, Kim DS, Choi ES, Shon HC, Park KJ. Comparison between suture anchor and transosseous suture for the modified-Brostrom procedure. Foot Ankle Int 2012;33:462-468.

27. Cho BK, Kim YM, Park KJ, Park JK, Kim DK. A prospective outcome and cost-effectiveness comparison between two ligament reattachment techniques using suture anchors for chronic ankle instability. Foot Ankle Int 2015;36:172-179.

28. Evans GA, Hardcastle P, Frenyo AD. Acute rupture of the lateral ligament of the ankle. To suture or not to suture? J Bone Joint Surg Br 1984;66:209-212.

29. Gould N, Seligson D, Gassman J. Early and late repair of lateral ligament of the ankle. Foot Ankle 1980;1:84-89.

30. Hamilton WG, Thompson FM, Snow SW. The modified Brostrom procedure for lateral ankle instability. Foot Ankle 1993;14:1-7.

31. Iwao K, Masataka D, Kohei F. Surgical reconstruction with the remnant ligament improves joint position sense as well as functional ankle instability: A 1-year follow-up study. ScientificWorldJournal 2014;2014:523902.

32. Jarvela T, Weitz H, Jarvela K, Alavaikko A. A novel reconstruction technique for chronic lateral ankle instability: Comparison to primary repair. Int Orthop 2002;26:314-317.

33. Jaskulka R, Fischer G, Schedl R. Injuries of the lateral ligaments of the ankle joint. Operative treatment and longterm results. Arch Orthop Trauma Surg 1988;107:217-221.

34. Jeong BO, Kim TY, Song WJ. Effect of preoperative stress radiographic findings on radiographic and clinical outcomes of the modified Brostrom procedure for chronic ankle instability. J Foot Ankle Surg 2016;55:125-128.
35. Karlsson J, Bergsten T, Lansinger O, Peterson L. Reconstruction of the lateral ligaments of the ankle for chronic lateral instability. J Bone Joint Surg Am 1988;70:581-588.

36. Karlsson J, Bergsten T, Lansinger O, Peterson L. Surgical treatment of chronic lateral instability of the ankle joint. A new procedure. Am J Sports Med 1989;17:268-273. discussion 73-74.

37. Karlsson J, Lundin O, Lind K, Styf J. Early mobilization versus immobilization after ankle ligament stabilization. Scand J Med Sci Sports 1999;9:299-303.

38. Karlsson J, Rudholm O, Bergsten T, Faxen E, Styf J. Early range of motion training after ligament reconstruction of the ankle joint. Knee Surg Sports Traumatol Arthrosc 1995;3: $173-177$.

39. Keller M, Grossman J, Caron M, Mendicino RW. Lateral ankle instability and the Brostrom-Gould procedure. J Foot Ankle Surg 1996;35:513-520.

40. Lofvenberg R, Karrholm J, Ahlgren O. Ligament reconstruction for ankle instability. A 5-year prospective RSA follow-up of 30 cases. Acta Orthop Scand 1994;65: 401-407.

41. Matsui K, Takao M, Miyamoto W, Matsushita T. Early recovery after arthroscopic repair compared with open repair of the anterior talofibular ligament for lateral instability of the ankle. Arch Orthop Trauma Surg 2016;136: 93-100.

42. Messer TM, Cummins CA, Ahn J, Kelikian AS. Outcome of the modified Brostrom procedure for chronic lateral ankle instability using suture anchors. Foot Ankle Int 2000;21:996-1003.

43. Petrera M, Dwyer T, Theodoropoulos JS, OgilvieHarris DJ. Short- to medium-term outcomes after a modified Brostrom repair for lateral ankle instability with immediate postoperative weightbearing. Am J Sports Med 2014;42:1542-1548.

44. Porter M, Shadbolt B, Ye X, Stuart R. Ankle lateral ligament augmentation versus the modified brostrom-gould procedure: A 5-year randomized controlled trial. Am J Sports Med 2019;47:659-666.

45. Russo A, Giacche P, Marcantoni E, Arrighi A, Molfetta L. Treatment of chronic lateral ankle instability using the Brostrom-Gould procedure in athletes: Long-term results. Joints 2016;4:94-97.

46. Saragaglia D, Fontanel F, Montbarbon E, Tourne Y, Picard F, Charbel A. Reconstruction of the lateral ankle ligaments using an inferior extensor retinaculum flap. Foot Ankle Int 1997;18:723-728.

47. Trichine F, Friha T, Boukabou A, Belaid L, Bouzidi T, Bouzitouna M. Surgical treatment of chronic lateral ankle instability using an inferior extensor retinaculum flap: A retrospective study. J Foot Ankle Surg 2018;57: 226-231.

48. Cho BK, Kim YM, Shon HC, Park KJ, Cha JK, Ha YW. A ligament reattachment technique for high-demand athletes with chronic ankle instability. J Foot Ankle Surg 2015:54:7-12.

49. Cho BK, Park KJ, Kim SW, Lee HJ, Choi SM. Minimal invasive suture-tape augmentation for chronic ankle instability. Foot Ankle Int 2015;36:1330-1338. 